\title{
13 Strategic spatial planning, "smart shrinking," and the deployment of CAVs in rural Japan
}

Ian Banerjee, Tomoyuki Furutani

$\begin{array}{lr}\text { 1. Introduction } & 240\end{array}$

2. Japan's demographic challenge $\quad 243$

$\begin{array}{lll}2.1 & \text { Population implosion } & 243\end{array}$

2.2 “Disappearing municipalities” 245

3. Evolution of national spatial planning 247

3.1 Achieving balanced growth: Comprehensive National Development Plans (1962-1998) 247

3.2 First responses to depopulation: Grand Design for the 21st Century (1998-2008) 247

3.3 A turning point: First National Spatial Strategy (2008) 248

3.4 The search for a grand narrative of change 249

$\begin{array}{llr}\text { 4. Governance } & 256\end{array}$

4.1 Structure of territorial government 256

$\begin{array}{lll}4.2 & \text { Two shifts in the approach to governance } & 257\end{array}$

5. CAVs in Japan $\quad \mathbf{2 5 8}$

5.1 The SIP: An institutional catalyst for cross-sectoral research 259

$\begin{array}{ll}5.2 & \text { NSS and CAVs } \\ 5.3 & 259\end{array}$

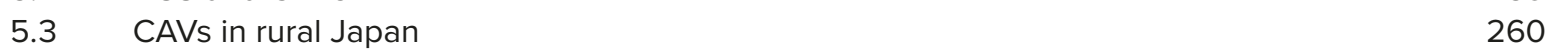

$\begin{array}{lr}\text { 6. Conclusion } & 264\end{array}$

$\begin{array}{lr}\text { Literature } & 267\end{array}$

Ian Banerjee

TU Wien, Research Unit of Sociology (ISRA)

ian.banerjee71@gmail.com

Tomoyuki Furutani

Keio University, Faculty of Policy Management

maunz@sfc.keio.ac.jp

(C) Der/die Autor(en) 2021

M. Mitteregger et al. (Hrsg.), AVENUE21. Politische und

planerische Aspekte der automatisierten Mobilität,

https://doi.org/10.1007/978-3-662-63354-0_13 


\section{INTRODUCTION}

The experiments taking place around connected and automated vehicles (CAVs) in global innovation networks today are largely technological in nature. This research takes a relational view of CAVs by investigating how they can be conceptualized within the larger context of strategic spatial planning. To do so, it takes Japan as a case study and explores how the current government is applying the tools of its new National Spatial Strategy (NSS) to strategically steer the development of its main economic and social sectors, including transport and the deployment of CAVs. All sectors of national innovation programs, including those for CAVs, are guided by the ideas and principles of the grand narrative of change envisioned by the new NSS (see fig. 1).

In the first publication of AVENUE21, Tokyo was presented, along with San Francisco, London, Gothenburg, and Singapore, as one of the pioneering regions for CAVs (see Mitteregger et al. 2020: 85-90). This research returns to Japan to take an in-depth view of the dynamic relations co-evolving between the country's new instruments of the NSS and the societal context of deploying CAVs. The main aim of this analysis is to find out if and how the device of a national spatial strategy can be helpful to conceptualize the potential deployment of CAVs. This research offers less a critique than an analysis of the rationale behind the newly adopted approach toward spatial planning in Japan, and the "new thinking" the government is struggling to embrace in order to cope with the country's daunting socioeconomic crisis. It spans an arc from the macro level of national spatial planning to the micro level of CAV tests conducted in rural Japan.

Before looking at an exemplary set of experiments conducted with automated mobility in rural Japan, we take an expansive view of the thematic issues and policy positions in the country. We argue that in order to understand the logic underlying the conceptualization of the potential deployment of CAVs in Japan, it is essential to understand the country's overall demographic, spatial, and economic predicament, and how the government wants to address the country's challenges with new ways of thinking about its future, new planning concepts, and new ideographic narratives.

Strategic spatial planning has often been criticized for being inherently neoliberal and autocratic, promoting gentrification and large-scale, profit-oriented urban development projects. However, planning theorists have also pointed to its potential to be inclusive, emancipatory, and innovative in socio-territorial terms (Swyngedouw et al. 2002, Moulaert et al. 2003, Bornstein 2007). This research seeks to explore its emancipatory potential, albeit in the very specific societal and cultural context of Japan. Despite the fact that the concept of strategic spatial planning has existed for many decades and has been proficiently practiced in countries of both the Global North and the Global South, it is difficult to find a shared definition. For this research, the we adopt the view of Oosterlinck et al. (2011) who define strategic spatial planning as "[...] a method for collectively re-imagining the possible futures of particular places and translating these into concrete priorities and action programmes" (Oosterlinck et al. 2011: 1; see also Albrechts 2004, 2006; Healey 2004). We look at strategic spatial planning not as conventional master planning pursued through passive control and zoning (Albrechts 2006) but as a "[...] transformative and integrative, (preferably) public sector-led socio-spatial process through which visions, coherent actions and means for implementation and co-production are developed, which shape and frame both what place is and what it might become" (Oosterlinck et al. 2011: 3, adapted from Albrechts 2006; see also Healey 1997, 2007). We also pursue an "institutionalist" understanding of planning, which is based more on a social-science-oriented planning theory than one that is planner-client oriented. This approach draws more attention to planning practices and the complex institutional dynamics connected to a place, changes in social relations, and the ways of collective decision making (for more, see van den Broeck 2011: 54). We assert that the conceptualization of the deployment of CAVs is shaped 
by the dynamic interlinkages between global, national, and particularly local factors. Its analysis on the local level is a challenging exercise in disentangling its cultural and institutional threads, and not to forget the threads of power and vested interests (see Stickler in this volume).

The reason for choosing Japan for this exploration is due to the opportunity it offers to study a nation's ongoing response to the severe demographic crisis it is facing today, with both the instruments of a comprehensive national spatial strategy and the resolve to deploy CAVs. The way the conceptualizations of new forms of mobility, including those of CAVs, are embedded in the larger framework of the country's new NSS, makes Japan stand out among the pioneering regions for CAVs.

The demographic crisis that Japan, the third-largest economy in the world, is facing today, is expected to reduce the country's current population by $30 \%$ by 2060 . Given the current trend and pace of depopulation in most parts of the country, the provision of utilities such as water, gas, public transport, etc., may become impossible to maintain in the coming decades. Ageing and radical depopulation of most of the countries' prefectures are already creating a substantial decrease in agglomeration potential and the loss of workforce. The crisis is unprecedented in history in terms of its magnitude and complexity. This seeming impasse has fueled the Japanese authorities' fear of economic downfall and partial collapse of the country's regional infrastructure. As in many other countries, response to depopulation has been slow; however, the current government has finally placed the topic as key item on its national policy agenda. Japan's main political objective today is to secure its national prosperity by revitalizing its economy, and to create sustainable settlement patterns that react to depopulation in creative ways. The political resolve to respond to the challenge manifested itself in the watershed year of 2014, when a number of ambitious economic and spatial restructuring strategies were simultaneously presented by various governmental institutions. This new thrust forward by the Japanese government has sparked considerable global interest in its policies. Japan is believed to be at the forefront of innovations addressing the challenges of ageing and shrinking in concerted ways-with mobility strategies and CAVs playing key roles therein (Roland Berger 2018, OECD 2016a).

This paper examines the government's response to the country's challenges along three analytical dimensions: spatial planning, governance, and mobility. It puts them in relation to each other after taking an historic view of the country's evolving approach toward planning, particularly taking into account the country's 60-year-long experience with the instruments of national spatial planning. The first section of this paper outlines the demographic challenge faced by Japan and the process of depopulation on the regional level. The second section reviews the evolution of national spatial strategies with a focus on the new grand narrative of a radically "compacted and networked" country inscribed in its two most comprehensive strategic responses: the National Grand Design 2050 (2014) and the 2nd National Spatial Strategy (2015). The third section examines the changing notion of governance by looking at how a consensus has been found among policy makers to transform Japan's traditionally centralized form of government into a multilevel form of governance by encouraging nationwide processes of participation from the bottom up. Finally, the fourth section looks at the new institutional setup created for the development of CAVs with a focus on their deployment especially in rural areas. It looks at how locally specific tests are conducted in rural and mountainous regions of the country, and at how a variety of factors are influencing the experiments with CAVs in these areas.

The research for this paper is based on a literature review and field experiences. We have drawn particularly on the comprehensive review of the new policies in Japan made by the OECD (2016a), the resources of the Ministry of Land, Infrastructure, Transport and Tourism (MLIT 2014, 2015, 2017, 2019), and the learnings from experiments conducted with CAVs at the Keio University in Tokyo. The presentations and discussions at the international conference SIPadus Workshop in Tokyo in November 2019 (SIP-adus 2019a) have also helped to sharpen the 


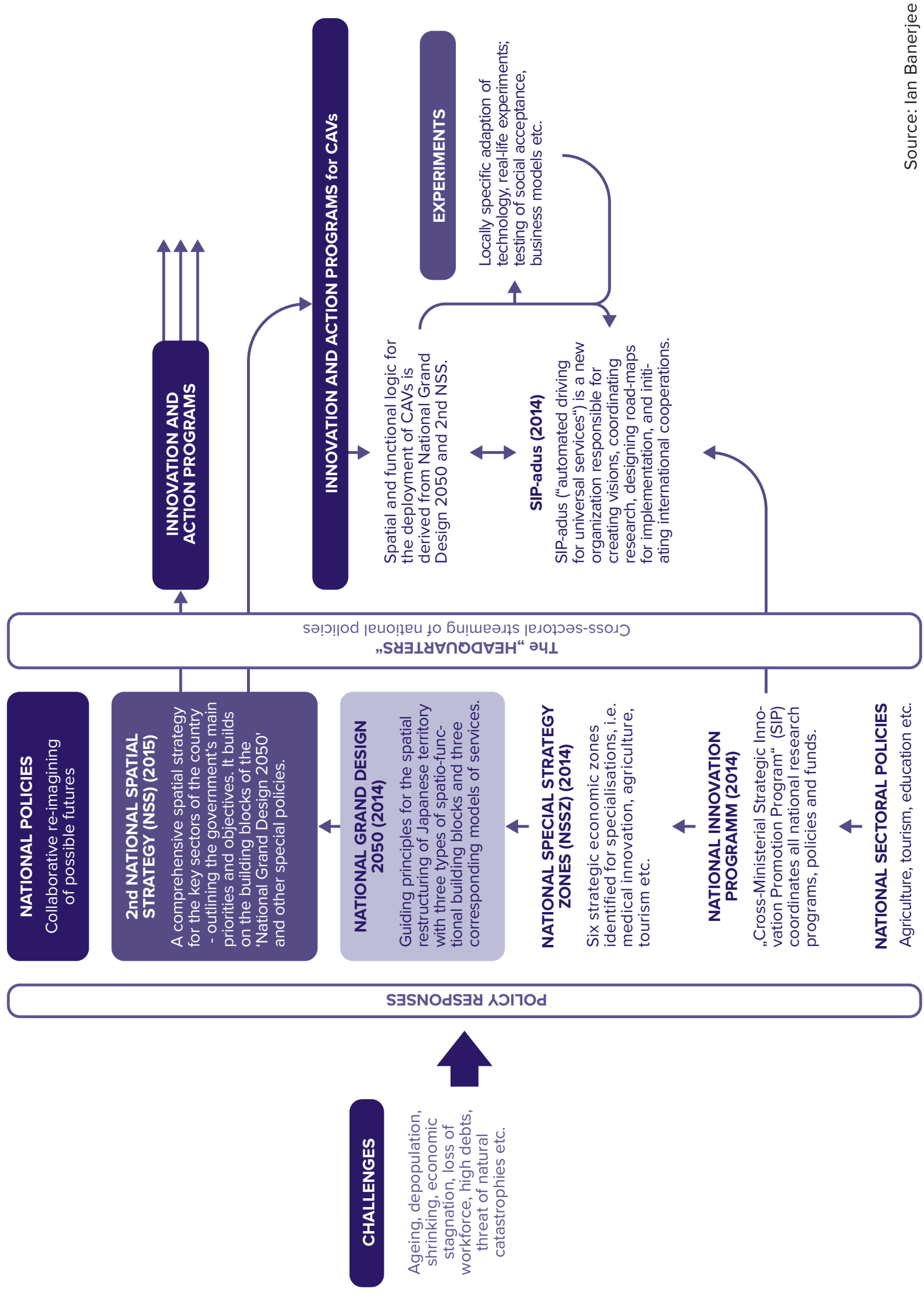


authors' picture of Japan's approach to connected and automated vehicles in comparison with other proactive countries in the field.

On the discursive level, this paper wants to contribute to the exchange of ideas between Japan and Europe. The necessity of learning from each other is timely for two pertinent reasons: both regions are facing the challenge of ageing (Reuters Graphics 2020) and the difficulty of serving their elderly population in rural areas; and both regions are interested in revitalizing their rural areas by making them more attractive places to live and work by, for example, deploying new mobility services such as those with CAVs.

\section{JAPAN'S DEMOGRAPHIC CHALLENGE}

\subsection{POPULATION IMPLOSION}

After the devastations of World War II, Japan surprised the world by swiftly rising to become the second-largest economy in the world, only to be recently overtaken by China. Here are some indicators of its success (for more, see Diamond 2019: 294-298): Today, Japan accounts for 8\% of global economic output; in the last decades, it has continuously managed to be among the top ten in the Global Competitiveness Index of the World Economic Forum; it is the world's leading creditor nation with the second-highest foreign exchange reserves (even though its high domestic debt draws more global attention); it has the world's best roads and one the densest infrastructure systems; it has the second-highest number of patents per million inhabitants; it makes the world's third-largest absolute investment in R\&D (after China and the USA); it is one of the cleanest and safest countries in the world, and the third-most equal country in terms of wealth distribution (after Denmark and Sweden).

After five decades of its spectacular display of techno-economic success, Japan now faces a composite crisis of a magnitude it has not seen since the beginning of the Meiji Restoration in 1868 (for more, see Diamond 2019). The eleventh-most populous country in the world (as per 2019) has today the highest proportion of elderly citizens of any country in the world, followed by Italy and Germany (Population Reference Bureau 2019). Ageing, the highest life expectancy in the world ( 80 years for men, 86 for women), the dramatic fall in fertility rates, and the subsequent shrinking of its regions have trapped the country in a series of chain reactions that are threatening to disrupt its economy, social contract, and geopolitical influence. Japan's population grew from 33 million in 1868 to 128 million in 2008 (fig. 2). After 60 years of growth, it is expected to shrink to 107 million (16\%) by 2040, to 97 million (24\%) by 2050, and to 86 million in 2060 (IPSS 2014, Funabashi 2018). After peaking around 2010, Japan's population is expected to fall back to around 50 million by the end of the century (Funabashi 2018); $40 \%$ of that population would be over 65 . The increase in the "oldest-old," namely those aged 75 and above, will more than double from 11\% in 2010 to $27 \%$ in 2060 (IPSS 2014, 2017). The demographic transition taking place in the country is unprecedented in human history (OECD 2016).

After at least two decades of neglect, the so-called "Masuda Report" appeared in 2014 to "galvanize a large part of the political elite" (OECD 2016: 194), particularly those living in the regions suffering population decline. The Masuda Report, with the original title of "Stop Declining Birth Rates: The Local Revitalisation Strategy," was named after the chairman of the Japan Policy Council (JPC) Hiroya Masuda, the former head of the Ministry of Internal Affairs and Communications (MIC). It triggered an impassioned nationwide debate and a call for radical action on governmen- 
Figure 2: Population trend by age group in Japan (1920-2060)

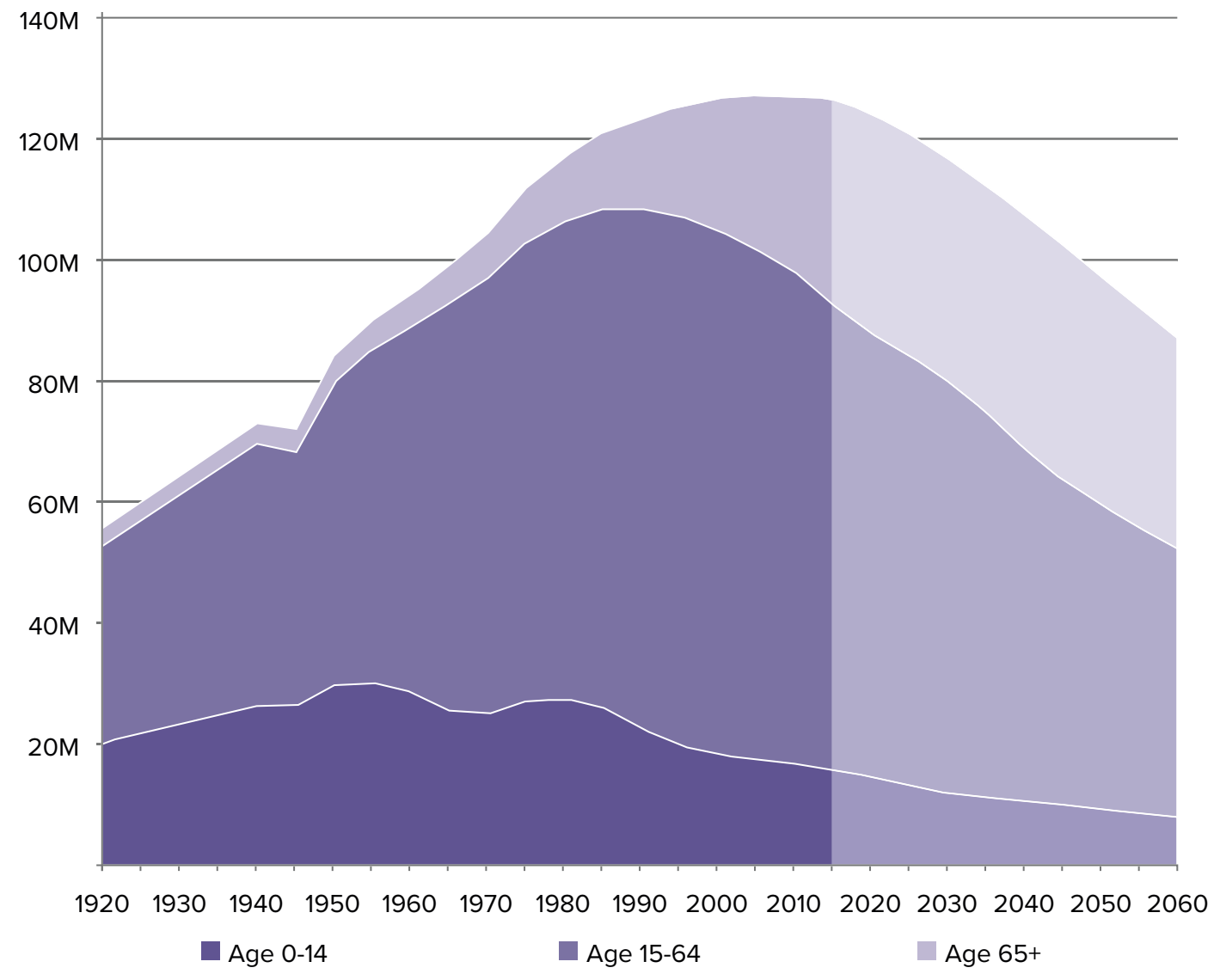

Source: IPSS $(2014,2017)$

tal and institutional levels. The report sent out the warning that 826 local governments, which is roughly half of the total, risked "extinction" by 2040 (OECD 2016: 195). The Masuda Report succeeded in transmitting its key messages with the help of succinct narratives. Its title "Stop Declining Birth Rates" pointed to the problem while at the same time making a plea for change. The second part of the title, "The Local Revitalisation Strategy," offered a solution to the problem and a recommendation for action, which, in principal, was about making "regional cities attractive to young people" by building "new structures of agglomeration" (OECD 2016: 195). It advocated the creation of "core regional cities" with 40,000 inhabitants connected to others with new information and transport technologies. These cities were to be attractive enough to function as "dams" against the outflow of young people into larger cities. The idea closely resembles the building blocks of the new National Grand Design 2050 that would follow that same year (see 3.4.2).

Four years after the Masuda Report, a scientific publication followed up on the same topic, carrying the title: “Japan's Population Implosion: The 50 Million Shock" (Funibashi et al. 2018). The editor, Yoichi Funabashi, backed by over a dozen authors, identified the policy failures of the last three decades and the lost opportunities to avert the impasse, making a passionate appeal for radical structural measures. It is one of the most comprehensive accounts of the demographic and social dilemma currently threatening Japan. The authors painted a dystopian picture of a coming catastrophe, showing how it had already begun in many regions. They pointed out that even though the population decline is tied to a multitude of other problems in Japan, it is not merely one problem among many but the key to understanding the principal structural deficiency afflicting the country (Webb 2018). 
While there are many reasons for population decline (see Diamond 2019), some, like Funibashi et al. (2018), link the central cause of the chronically low fertility rate in Japan to the lack of work-life balance and the intense stress factors citizens are exposed to in their everyday lives, leading to "[...] a sense of fatigue [...] in Japanese workers, especially young workers with long commutes, extensive overtime, and ambiguous personnel evaluation systems" (Funibashi et al. 2018: 104). They argue that Japan's birth rate will not recover without a fundamental reform of the social structures that are threatening interpersonal relationships and deterring citizens from marriage and childbirth (Funibashi et al. 2018: 103).

\section{2 "DISAPPEARING MUNICIPALITIES"}

Socio-spatial data shows that the population decline in Japan has been relatively slow and spatially uneven in the last decades. Between 1985 and 2010 it was less than $10 \%$ in five prefectures with the highest rate of decline. Some prefectures even saw an increase in their population during this period. It was only after 2008 , when the population started to plummet as a whole, that it became prevalent for almost all of Japan. The term "disappearing municipalities" is commonly used in the discourse to concisely depict the fate of a large number of municipalities affected by depopulation and ageing. Most prefectures in Japan will only have 50 to $70 \%$ of their 2010 population count by 2060 (Funibashi 2018: 52). According to Japan's Regional Population Projections (IPSS 2014), the rate of decline in 42 prefectures (out of 47) will be more than 10\% between 2020 and 2040.

Figure 3: Population projections for municipalities from 2010 to 2060 . Figures after 2040 were extrapolated by the IPSS authors from the same hypothetical figure

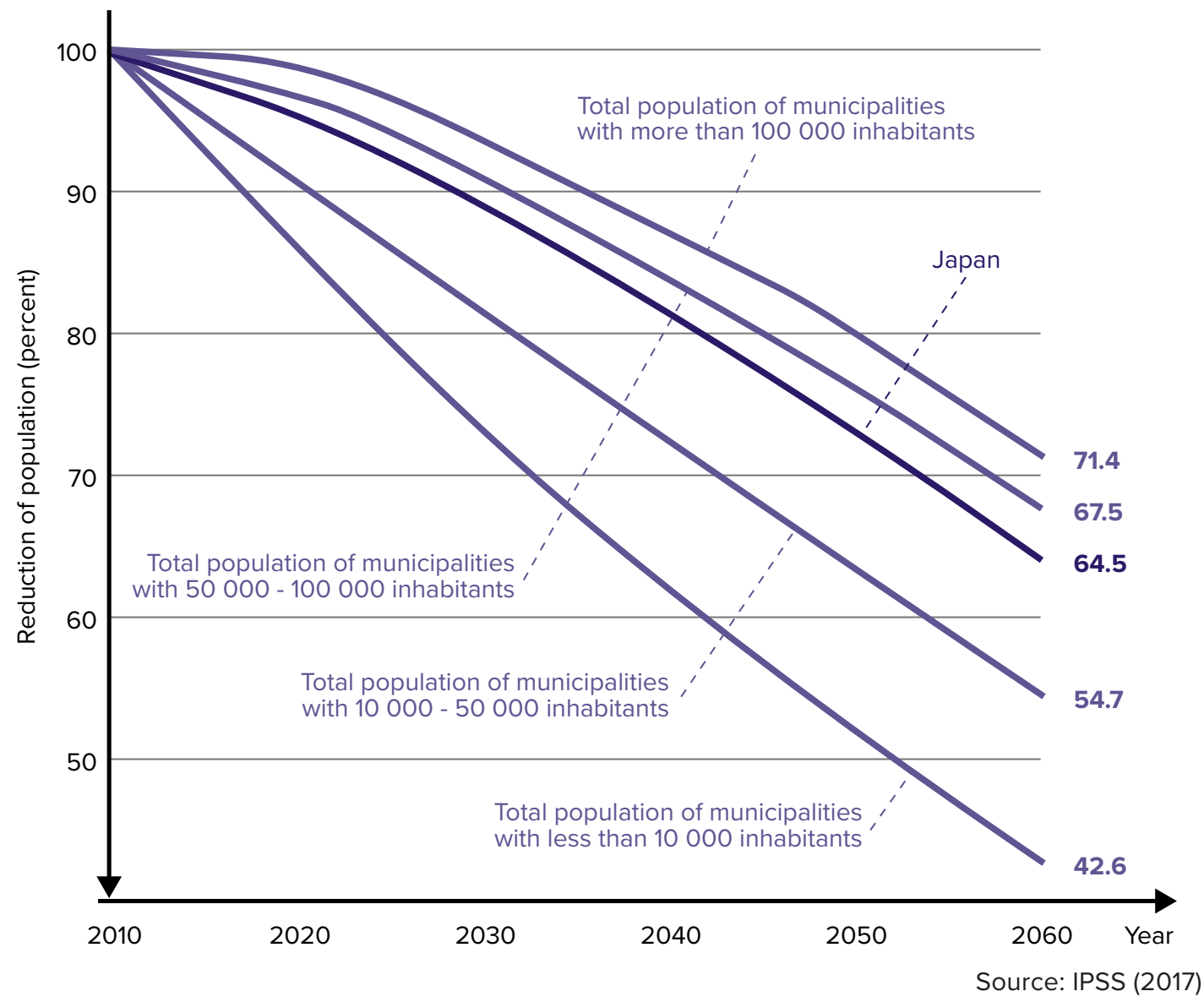


The reason for the drop in regional population, in addition to the general drop in fertility rates, is largely due to rural-to-urban migration. After World War II, a large number of young people started to migrate to three large metropolitan regions: (1) Tokyo, Chiba, Saitama, and Kanagawa; (2) Aichi, Gifa, and Mie; and (3) Osaka, Kyoto, Hyogo, and Nara. Today, roughly half of Japan's population lives in these three regions. With their rapid industrial growth and global economic success, these three regions started to attract large numbers of young people from rural areas-a trend that continued until around 2005. During the high growth era of the booming 1960s when Japan grew into a global economic powerhouse, more than 600,000 graduate students would flock to these three regions every year (Funibashi 2018: 54). Today, in 2020, the number is around 100,000 per year. The aged population ratio will start to affect these mega metropolitan areas slightly later than rest of Japan, that is, from around 2030 (Kaneko/Kiuchi 2018: 11). This will be the time when Japan will have "a real sense of population decline" (Funabashi 2018: 52). By 2060 , the population is expected to be less than or equal to half of the current level in about half of the municipalities nationwide. $70 \%$ of all municipalities are likely to see a reduction of around $20 \%$. Forecasts show that the smaller the size of the municipality, the faster the speed of decline will be (fig. 3). Towns and villages with 10,000 or fewer inhabitants are expected to have approximately 40\% of the current figures by 2060 (Funabashi 2018: 54).

Urban population decline is known to create a dangerous chain of events that usually triggers a sustained downward spiral (OECD 2016: 233). It can lead to migration, erosion of human capital, the downsizing of services, reduction of opportunities available locally, reduction of real estate values, etc. The pressure on financing public services will mount as local tax revenues decline and the per person cost of providing services rises. This will then lead to the closure of schools, hospitals, and public facilities (see fig. 4).

Figure 4: The possible consequences of population decline

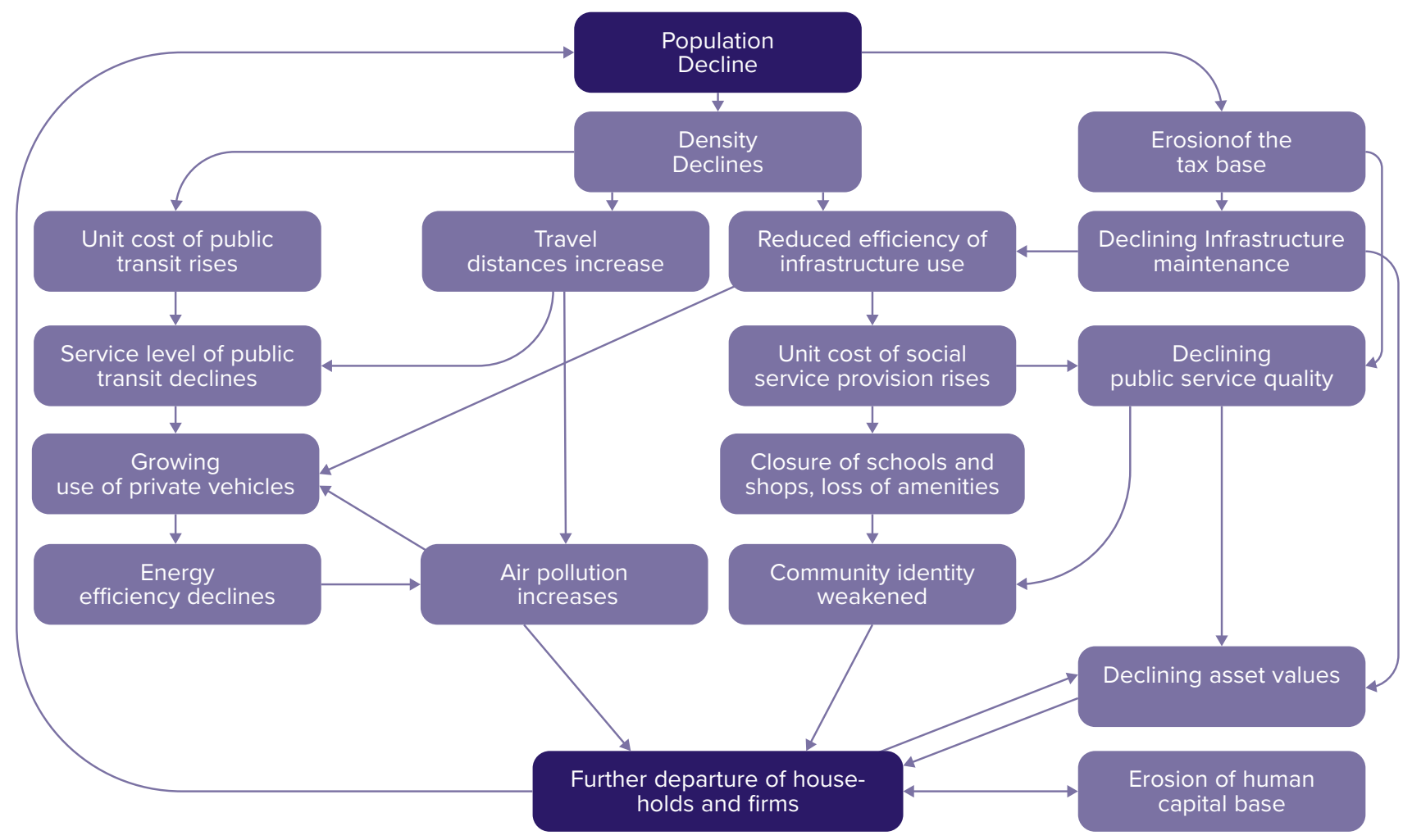




\title{
3. EVOLUTION OF NATIONAL SPATIAL PLANNING
}

\subsection{ACHIEVING BALANCED GROWTH: COMPREHENSIVE NATIONAL DEVELOPMENT PLANS (1962-1998)}

\begin{abstract}
Over the past 60 years, Japan has experienced profound changes in its socioeconomic condition including rapid acceleration of industrialization and a fast increase in its population. During this period, while the country soared to become the second-largest economy in the world, the Japanese government practiced national-level spatial planning with the aim of alleviating spatial disparities and steering the country's economy in a balanced way. The first Comprehensive National Development Plan (CNDP) was published in 1962, with three subsequent CNDPs following in 1969, 1977, and 1987. The strategic plans generated idealized visions of the Japanese territory, addressing issues like land use, industrial locations, social infrastructure, culture, tourism, natural resources, human resources, etc. For 50 years, the CNDPs remained the main steering instrument for Japanese national and regional land policies (Ono 2008), leading the country into an era of unprecedented wealth.
\end{abstract}

\subsection{FIRST RESPONSES TO DEPOPULATION: GRAND DESIGN FOR THE 21ST CENTURY (1998-2008)}

50 years of high growth rates and relative regional stability of the population and settlement structures in Japan ended in the 1990s. After the collapse of the dot-com bubble in 1993, the Japanese economy started to slide into stagnation, and by the end of the century, the specter of depopulation had started to emerge in the public discourse. At this turning point, the concept of CNDP was sidelined and a new framework for the country's spatial strategy was presented in 1998: the Grand Design for the 21st Century. The Grand Design was not only a spatial strategy but also addressed a broader range of issues such as the consequences of globalization, the revolution in information technologies, and very importantly, the country's demographic situation (OECD 2016: 86). Also, it advocated a multiaxial development plan as a long-term vision, marking for the first time a departure from the excessive dependence on the economic engine of the Tokyo megaregion (Ono 2008). Also for the first time, it began to promote wider citizen participation (Ono 2008).

\subsubsection{Compact City and Transport-Oriented Design (TOD)}

The 1998 "Act on Vitalization in City Centers" was the first attempt to strategically incentivize the concentration of urban functions and invigorate commercial activities in city centers while striving to minimize the role of the central government.

The first tangible and design-oriented spatial policy that responded to depopulation started with the increasingly popular metaphor and concept of the "compact city." While national and local governments started debating various ways to enact new laws to reinvigorate shrinking city centers, Aomori City (population: 287,000) and Toyama City (population: 415,000) were the first cities to respond proactively to the situation (Kikodoru et al. 2008: 16). Based on the idea of the compact city, they drew up master plans in 1998 that would incentivize the concentration of urban functions in city centers in order to save the costs of maintaining public facilities, 
conserve energy, and prevent further urban sprawl (OECD 2012, Kaneko/Kiuchi 2018). These attempts demonstrate the early adoption of Transport-Oriented Design (TOD) in Japan, which focuses on creating public transport and new urban centers along the transportation axes of railways and buses, and encourages the building of housing and medical services near stations and bus stops. Toyama City, in particular, promoted "active mobility" by encouraging urban development that facilitates access to functions within walking distance.

In 2005, the Sectional Committee on Urban Planning and Historic Landscape of the Panel on Infrastructure Development wrote an initial report on the need for "urban restructuring" by replacing existing urban structures with "concentrated" urban structures. They proposed the concentration of commercial, administrative, medical, cultural, and other functions to ensure accessibility without reliance on cars (Kaneko/Kiuchi 2018). Three revised acts strengthened the involvement of local governments to set and evaluate measurable targets.

\subsection{A TURNING POINT: FIRST NATIONAL SPATIAL STRATEGY (2008)}

Despite the initial efforts to concentrate urban functions, the outcomes of the new measures remained limited and urban sprawl continued. After the first Grand Design, which had sketched out a broader view of the country's future, in 2005 the 1962 legislation of CNDPs was fundamentally revised and renamed the National Spatial Planning Act. The new act constituted an important shift: from a growth-driven planning regime to one concerned with demographic decline and the sustainable use of national territory (OECD 2016). Most significantly, the new strategy also started to look at how to promote more autonomy for local governments. In 2006, eight local regions were defined and asked to prepare their own regional spatial plans (RSPs; ONO 2008), which were to be subsequently integrated into the National Spatial Strategy (NSS). The 1st National Spatial Strategy (1st NSS) was finally adopted in 2008. With the depopulation debate in full swing and the economic stagnation turning into a serious problem, this marked a major turning point for Japan.

\subsubsection{Low-Carbon City (2012)}

In November 2012, the Ministry of Land, Infrastructure, Transport and Tourism (MLIT) presented directions for a new policy with basic guidelines toward sustainable development by promoting "regional intensification" by encouraging the construction of green buildings and the use of low-carbon and recyclable systems. This led to the enactment of the Act on Promotion of Low-Carbon Cites in December 2012 (Kaneko/Kiuchi 2018). Thus, two policy narratives, the "compact city" and the "low-carbon city," began to shape the urban discourse in the country. The new plan allowed local governments to create their own ways to promote the low-carbon city in so-called "Urbanization Promotion Areas." Reduction in income tax, relaxation of certain regulations, and financial support through subsidies were offered as incentives. By October 2014, sixteen cities had been designated to be low carbon.

The two cities in Japan that are often mentioned as a reference in this context are Maebashi City and Kochi City. Maebashi City produces around 40\% more annual $\mathrm{CO} 2$ emissions per person in the transportation sector than Kochi City. The reasons for this difference lie in the different forms of the cities and their different degrees of spatial compactness (Kaneko/Kiuchi 2018: 22). This comparison is often brought forward as an argument for promoting a combination of the low-carbon city and the compact city concepts. 


\subsection{THE SEARCH FOR A GRAND NARRATIVE OF CHANGE}

\subsubsection{Scenarios of hope: Reframing the problem}

The reluctance to accept the grim prospects of shrinkage as something permanent, as observed in other parts of the world, may be due to electoral reasons or simply because of a natural human unwillingness to believe oneself to be part of a declining community (Schlappa/ Neill 2013). A large number of medium-sized cities in OECD countries are facing similar challenges, yet there is a remarkable lack of good practices to be found in the field. The dominant narrative of growth has created an all-pervasive paradigm and institutional mindset that drives the vested interests of the infrastructure industry of most countries through the "iron triangle" linking bureaucracy, politics, and business (Adams 1981). This may also be a contributing factor to why governments are slow to respond to the situation.

As the image of the forbidding reality of depopulation started to trickle down into the consciousness of Japanese society, policy makers found themselves compelled to create scenarios that conveyed some elements of hope to bring back confidence into a society growing progressively pessimistic. The year 2014 marked a watershed moment for the generation of such scenarios of hope. That year, while the scathing Masuda Report was circulating, the government proposed a number of ambitious spatial and functional restructuring strategies. It is interesting to see how these strategies could reframe the bleak forecasts of recent years with narratives of opportunities and potentials. For example, "disappearing municipalities" and "shrinking cities" became "smart shrinking" or "rightsizing cities." Population decline, undoubtedly a daunting challenge, was framed in a way that it could offer new opportunities. This narrative shift was an important step toward sparking community action and institutional change within a wide range of social networks.

\subsubsection{A culmination point: National Grand Design 2050 (2014)}

Two decades of debates on depopulation and economic stagnation culminated in a framework for a coherent and long-term spatial development strategy that, finally, squarely addressed Japan's sociodemographic crisis: the "National Grand Design 2050: Creation of a country generating diverse synergies among regions," was unveiled by the Ministry of Land, Infrastructure, Transport and Tourism (MLIT) in 2014 (OECD 2016, Funabashi 2018). The new Grand Design identified the main trends and challenges as the ageing population, depopulation, ageing infrastructure, increasing competition between cities, natural disasters, technological change, and threats to food, water, and energy supply (MLIT 2014). It formulated its key strategies based on a new population count founded on a national grid, of which more than $60 \%$ was assumed would lose half its population. $20 \%$ of these grid squares were forecasted to become uninhabited by 2050 (MLIT 2015). Based on the identified trends and challenges, the Grand Design 2050 created the principles for a long-term spatial strategy up to 2050. These were subsequently integrated into all other government plans, including the most important-the 2nd National Spatial Strategy-to be adopted the following year.

\subsubsection{Smart Shrinking: The principles of the National Grand Design 2050}

The two main ideographic narratives of the strategy are "compact" and "networks." The new Grand Design suggests the "rightsizing" of cities and the creation of new types of functionally connected regions. It proposes a spatial restructuring of the entire Japanese territory with three types of spatio-functional building blocks and three corresponding models of services (Amano/Uchimura 2018, OECD 2016). These are: (1) villages with "small stations," (2) mid-sized 
cities with "integrated regional hubs," and (3) a "super megaregion" around Tokyo with "collaborative core urban areas." Before elaborating on the spatial building blocks, we shall have a look at the key components and principles underlying the strategy.

\section{Compacted and networked}

The two principle ideas underlying the strategy are: (a) to make the country spatially more "compact" in order to make public service delivery efficient and supportable; and (b) to strategically interlink the compacted areas into larger functional "networks" with the hope of creating more innovation by intensifying processes of exchange between neighboring regions. It is assumed that this will help to maintain or regain the agglomeration effects lost by depopulation, and to nurture the engines of growth by radically improving the connectivity infrastructure between the regions.

Figure 5: "Smart Shrinking": diagram of the key ideas and principles of the National Grand Design 2050 and the 2nd NSS

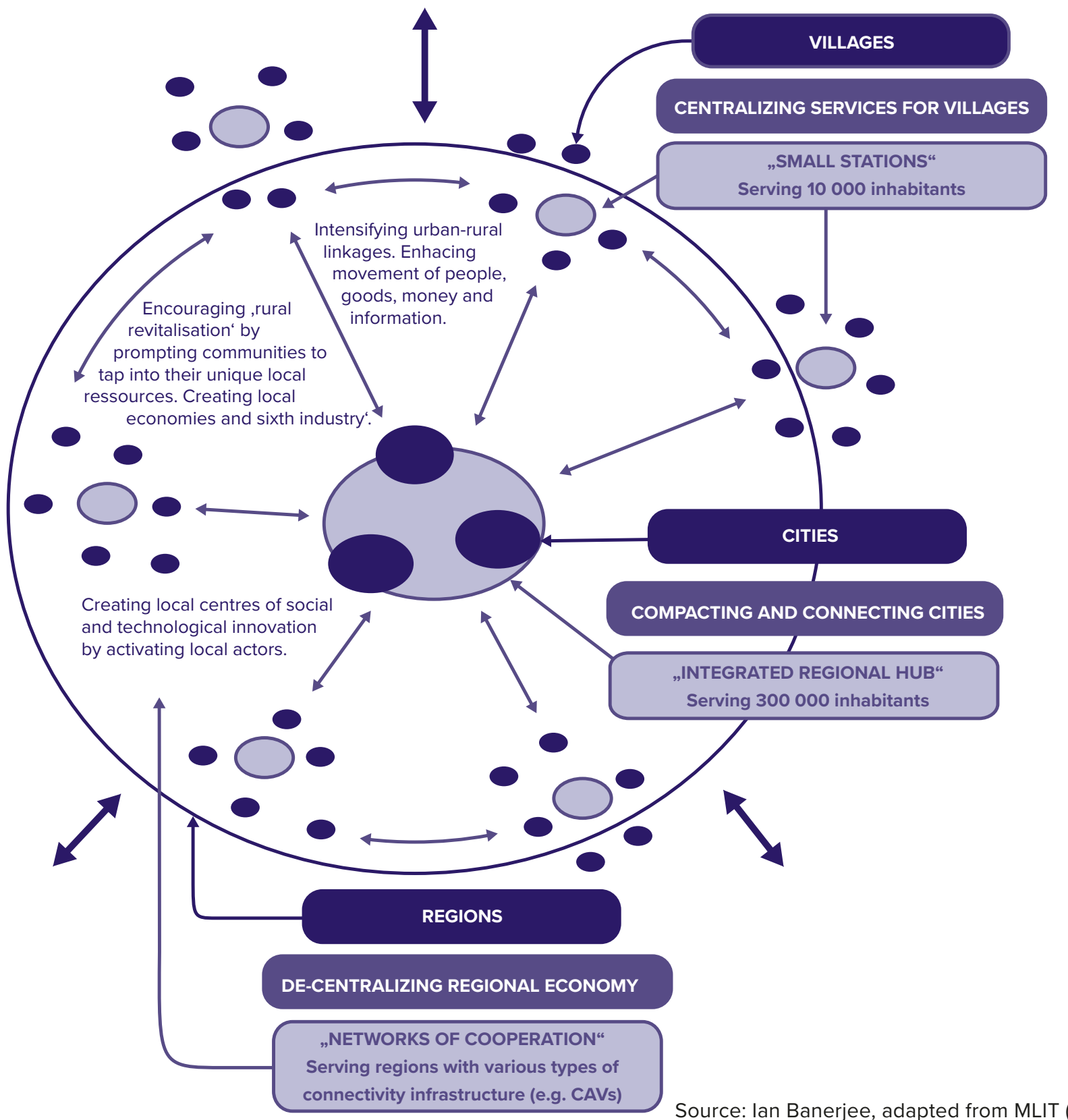

Source: Ian Banerjee, adapted from MLIT (2014) 
The principle ideas of the Grand Design mainly take their cue from studies in economic geography and location theories. They are based on research showing that the doubling of the population living within a radius of $300 \mathrm{~km}$ can increase productivity by 1.0 to $1.5 \%$ through various forms of spillover (OECD 2015). While there is overwhelming evidence that economic benefits can increase with city size, there is also evidence that smaller cities can benefit by "borrowing" agglomeration from neighboring cities (OECD 2016: 84). Agglomeration effects are believed to result not only from population density but from "the ease with which agents can interact and transact with a large number of other agents" (OECD 2016: 84). Also, studies show that these interactions do not necessarily have to take place only in close vicinity-many highly innovative regions are successful by being part of international linkages despite having moderate populations.

The principles of the Grand Design also remind us of the Central Place Theory (CPT), a highly influential yet disputed theory put forward by the German geographer Walter Christaller in the 1930s (Christaller 1933). Based on the analysis of existing human settlements in Southern Germany at the time, Christaller proposed an idealized model for planning settlements based on the concept of centralization as ordering principle. He asserted that settlements existed as "central places" to host services for surrounding areas. According to Christaller, people purchased goods and services from the closest places, and in the transportation model this ordering could minimize the network length and maximize the connectivity of the centers to be served (Agarwal 2009). Building on this, he argued it would be possible to calculate the size and number of settlements, evenly distributed across the entire territory, using the hierarchical order of space built on hexagons. While there are striking similarities between the principles recommended by the new spatial strategy in Japan and CPT, it is notable that the precondition of Japan is radical shrinking, while CPT was conceptualized in times of growth.

Figure 6: The hierarchic ordering of space according to the Central Place Theory of Walter Christaller

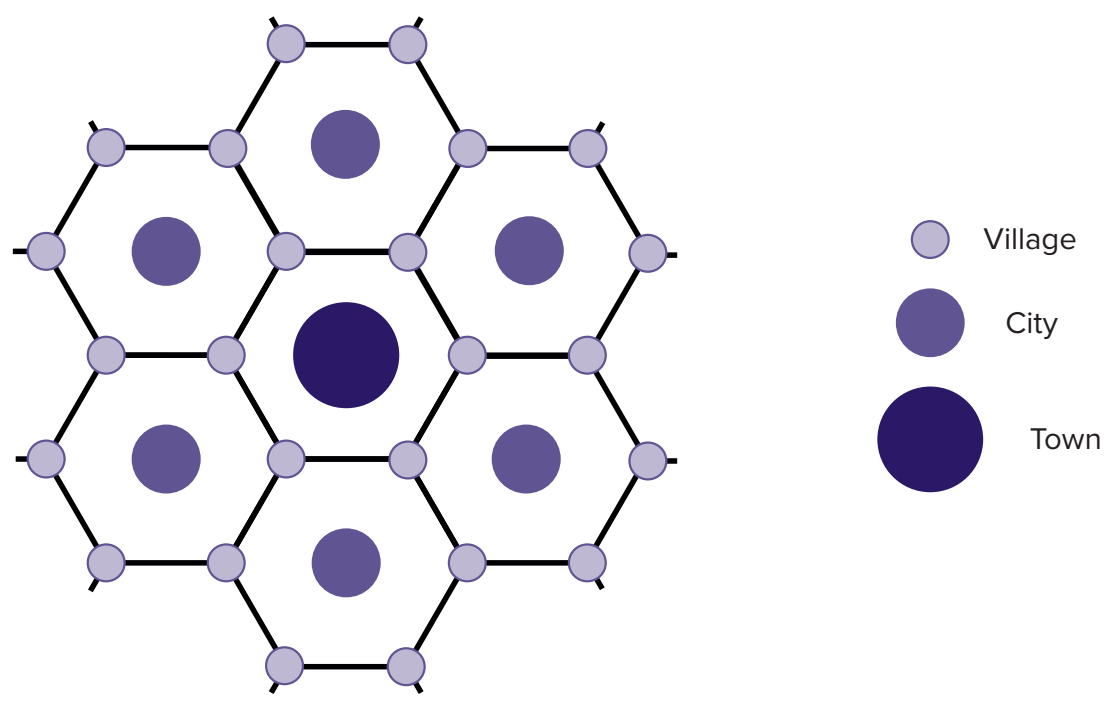

Source: Ian Banerjee, adapted from Christaller (1933)

\section{Diversity and collaboration}

As the subtitle of the Grand Design suggests, it is about the "Creation of a country generating diverse synergies among regions" (MLIT 2014). Diversity and collaboration are seen here as preconditions for regional development in times of depopulation (MLIT 2014; OECD 2016b: 10). Regions and towns are encouraged to identify their specific natural, cultural, economic, and social assets and understand their potential to attract people and investment: "This very diversity 
of endowments and strategies creates the possibility for collaboration, because it gives rise to the possibility of identifying potential complementarities among places and building strategies to exploit them" (OECD 2016b: 10).

Economic diversification in regions along with intensified interactions are expected to lead to more "constructive dialogues" between people and places (MLIT 2015: 31): "As the population declines, competition among regions and cities for people and resources will intensify, largely because they have similar endowments, needs and aspirations. However, it is their diversity that may offer the best hope for the future" (OECD 2016b: 10). The new strategy recommends experiments with models of governance that foster new types of political cooperation between regions (see section 4).

\section{Rural revitalization and the "sixth industry"}

The main reason for migration to big cities in Japan (and most other countries) is the lure of jobs and lifestyle. The only way to prevent this is believed to be the revitalization of rural areas with the creation of non-agricultural jobs and the provision of lifestyle options attractive to the younger cohorts. As a response to this challenge, the Grand Design has taken up the narrative of "rural revitalization." The "compacting" of territory is not seen merely as a defensive measure to streamline services for shrinking regions; instead, it urges regional governments to embrace innovative approaches toward building new foundations for economic activities in rural areas (OECD 2016: 81; MLIT 2015). This also includes strategies around stimulating senior entrepreneurship known as the "silver economy" and the "sixth industry."

The sixth industry is essentially about "the formation of integrated value chains encompassing production, distribution and marketing by linking agriculture, forestry and fisheries producers to those with expertise in the secondary (processing) and tertiary (marketing) sectors [...]" (OECD 2016: 213). Such strategies are built on local assets exemplified by the logic of strategies like those used in France to market products such as French wine or local cheeses. A number of lighthouse projects in Japan provide good examples of how small towns have been able to reinvent their economies and even create new regional identities by tapping into their local resources. For example, the Seiwa area in Mie Prefecture was able to create a buzz around environmental innovation; AmaCho in Shimane Prefecture has been able to shine with food technology and education; and very prominently, Kamiyama in Tokushima Prefecture has found success with IT companies and art. All have established a basis for future prosperity and created conditions that are attractive to young people, without the unrealistic desire to "bounce back" to their previous population counts.

Attractive rural landscapes and amenities, combined with good external connectivity, are leading to the rise of a growing number of start-ups in the field known as "knowledge-intensive service activities" (KISA). This trend can be also observed across many OECD countries (OECD 2016b: 17). The sixth industry and KISA are not expected to have a substantial macroeconomic impact in Japan, but it is anticipated that "small niche activities could still make a big difference in thinly populated areas" (OECD 2016a: 211). A considerable part of the process of reimagining the future of Japan will be about how to create prosperity with fewer people.

\section{Intensifying urban-rural linkages}

Making rural life attractive to younger cohorts is seen as an essential task by the government. The Grand Design recommends strengthening relationships between rural areas and urban residents by creating stronger "urban-rural linkages." The experience of new types of rural life is actively promoted by initiatives such as "Attractive Rural Areas-Make Coming Back to Rural Areas Real," put forward by the Ministry of Agriculture, Forestry and Fisheries (MAFF) in 2015. It is broken down into very simple projects, such as enhancing children's understanding of rural life by offering experience-rich tours, or encouraging direct exchanges of goods and services between various sectors and industries. 


\subsubsection{The three spatio-functional building blocks}

The Grand Design 2050 reimagines the reconfiguration of Japanese territory with three types of spatio-functional building blocks based on three spatial scales and three models of social services. They are conceptualized as follows.

\section{Villages served by "small stations" (serving 10,000 inhabitants)}

It is recommended that the villages, where most of the population decline is expected to take place, are interlinked into networks of villages of a defined size and served by centralized community service delivery hubs called "small stations." These stations have two functions: to offer services and to help gather people, goods, money, and information to create new value. They offer life services such as childcare, health/elderly care, government information, etc. Each of these small stations could serve up to 10,000 inhabitants in the village network. Estimates show around 5,000 to 7,000 of them would need to be constructed across the country (OECD 2016: 82). For example, Kochi Prefecture on the island of Shikoku plans to build 130 such stations, positioned 4 to $5 \mathrm{~km}$ from each other, within a catchment area of $54 \mathrm{~km} 2$. Studies by the National Institute for Land and Infrastructure Management (NILIM) have mapped out the measures necessary to push forward the "systematic shrinking of urban areas," which might be necessary when restructuring the urban areas through

Figure 7: "Small stations" are places offering centralized public services for surrounding villages for around 10,000 inhabitants. They are also places for gathering, bundling resources, and creating new values. New models of transport and mobility (including CAVs) are conceptualized in an ongoing process

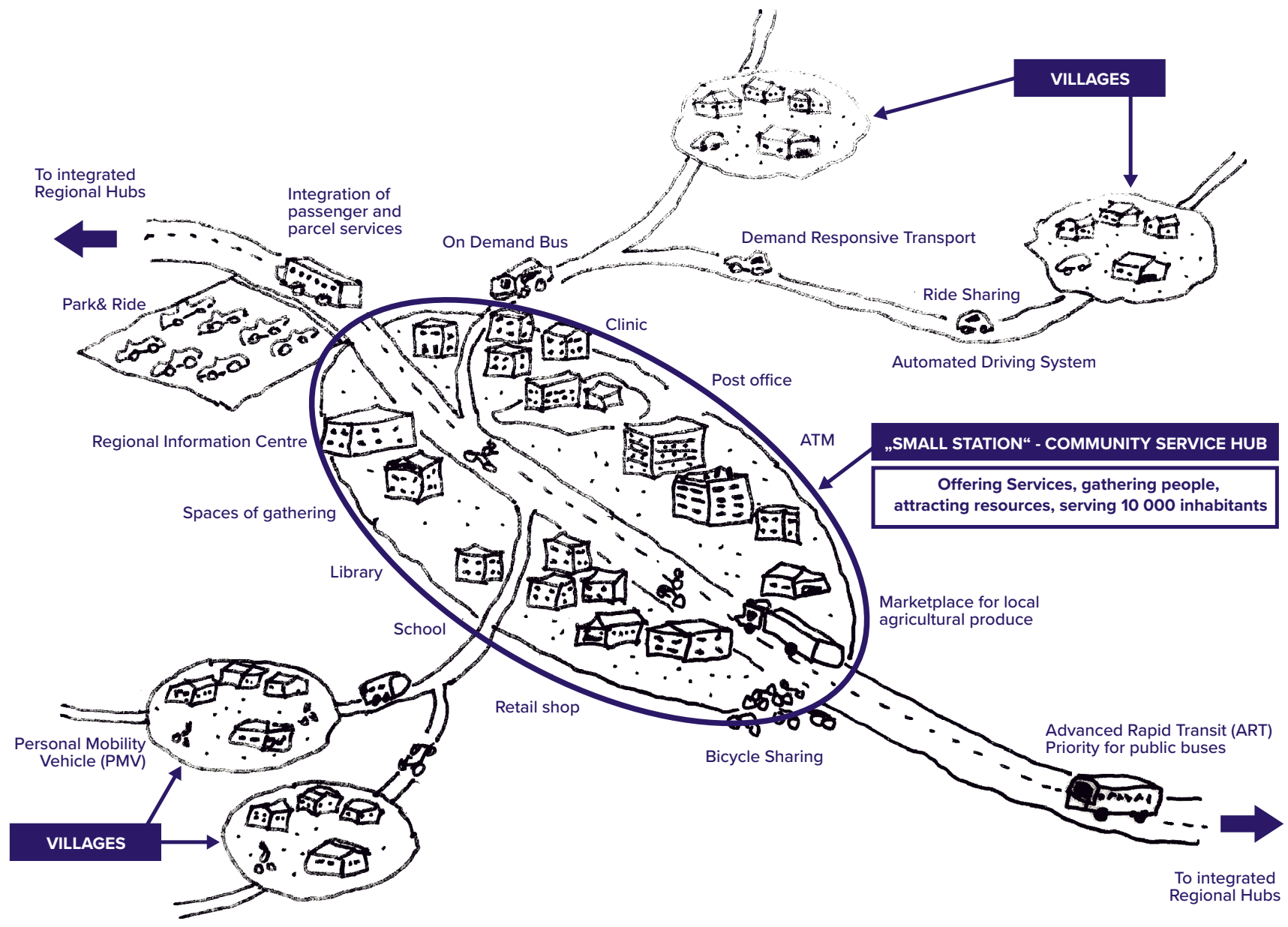

Source: Ian Banerjee; adapted from MLIT (2014) 
these small stations (Kaneko/Kiuchi 2018: 22). The politically and socially difficult question of relocation has often been discussed but mostly rejected by citizens (SIP-adus 2019a).

The deployment of CAVs with different capacities and ranges is expected to help create mobility services for these small stations. It is important to note that the aim of the strategy is to reduce car dependency and urban sprawl; the strategy promotes the concentration of key urban functions along with the extension of public transport networks (OECD 2016).

\title{
Mid-sized cities served with "integrated regional hubs" (serving 300,000 inhabitants)
}

The strategy recommends the integration of mid-sized cities into functional urban areas (FUA) with a combined population of at least 300,000 . This rationale is based on the assumption that a population of 300,000 is necessary to offer and maintain high standards in education, medical care, and employment opportunities. They will be served through "integrated regional hubs," also called "urban compact hubs." These hubs will be connected with each other within one hour of travel ("high-grade city links"). The strategy estimates Japan would need 60 to 70 such regional hubs (Amano/Uchimura 2018: 23).

\begin{abstract}
A "super megaregion" served by "collaborative core urban areas"
The aim of creating a "super megaregion" is to enhance the agglomeration potential of Tokyo. Against the backdrop of the country's stagnating economy, this is of particular national interest. As often mentioned in the urban discourse, along with New York and London, Tokyo is one of the world's top three "global cities" (Sassen 2001). It represents a crucial aspect of the country's economic competitiveness and also its cultural landscape. The future of Tokyo is an important
\end{abstract}

Figure 8: "Integrated regional hubs" are integrated functional urban areas (FUR) serving 300,000 inhabitants. These are places offering high-end services such as education, health, etc. Better physical and digital connectivity are expected to make these places more innovative and productive

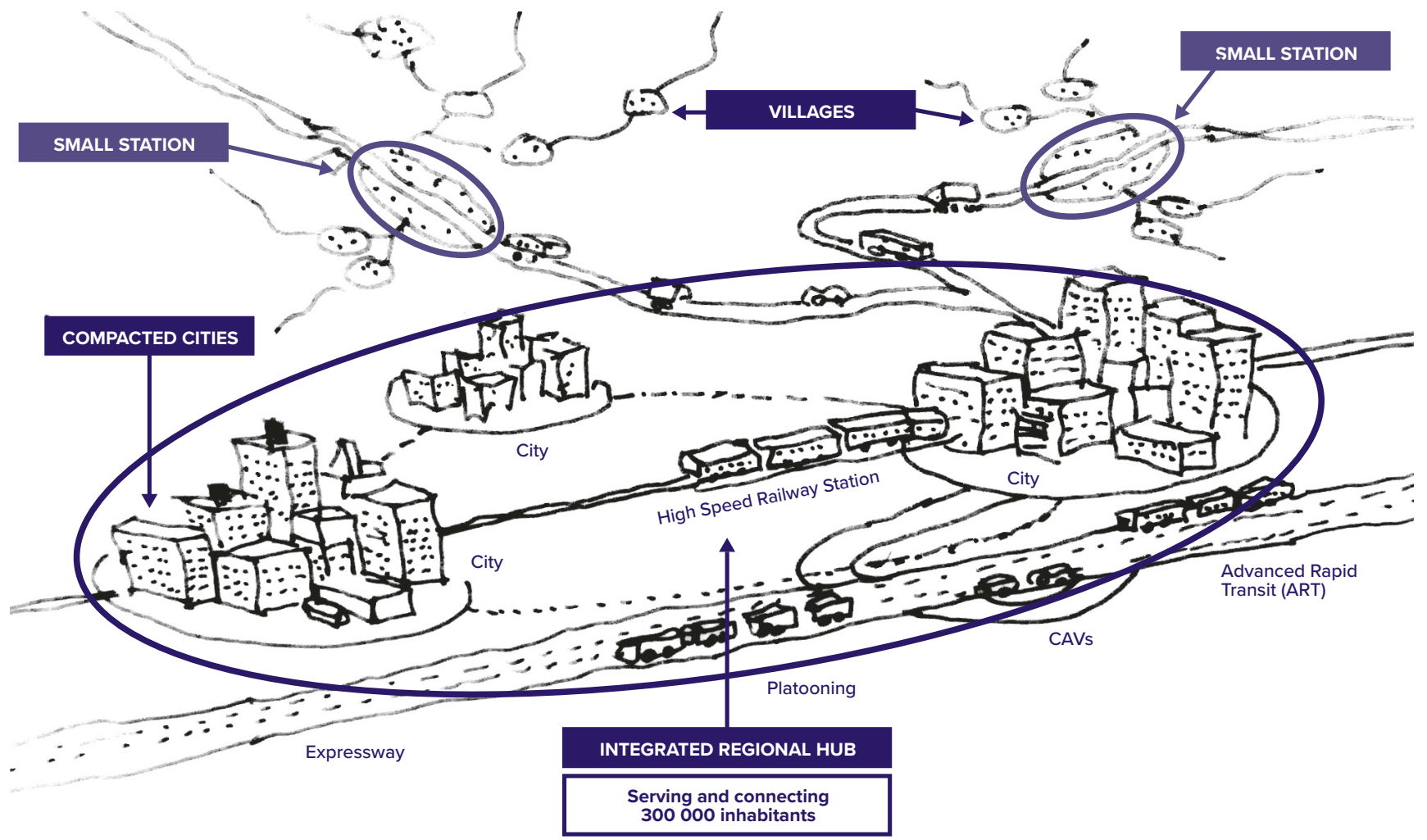


and sensitive topic for national spatial planning in Japan. The idea put forward by the strategy is to create more intense physical and digital connectivity between the three metropolitan regions of Tokyo, Nagoya, and Osaka by connecting them with high-speed internet and an ultrahigh-speed train (maglev) called Chuo-Shinkansen. This will make them physically reachable within an hour. With 64 million inhabitants, this will be the largest functional urban region (FUR) in the world. To maintain their competitive edge in logistics, innovation, and knowledge creation, these regions are expected to need the services of a wider range of specialized forms of financial, business, and producer services. The new strategy aims to achieve a higher concentration of such high-level urban services by building "collaborative core urban areas" situated near railway stations and other central locations (OECD 2016: 158).

\subsubsection{2nd National Spatial Strategy: A comprehensive planning device (2015-)}

The 2 nd NSS, adopted by the national government in 2015, currently serves as the most important socioeconomic planning document for Japan (for an English summary, see MLIT 2015). It integrates the building blocks of the National Grand Vision 2050 and outlines a comprehensive spatial strategy addressing all sectors of development. Also, with reference to Japan's geopolitical interest, it recommends the intensification of transnational exchanges with other regions in Asia, particularly with Southeast Asia (for more, see MLIT 2015).

Its overarching objectives are: (a) revitalizing regional and rural economies, (b) creating new settlement patterns by "smart shrinking," and (c) strengthening the global competitiveness of the major metropolitan areas. The architecture of the 2 nd NSS reflects a consistent, long-term vision of the government's response to population decline. It formulates the nation's priorities and objectives while ensuring the coherence of the main sectoral policies, including the above-mentioned eight regional spatial strategies. In particular, the NSS includes the country's economic strategies, such as the National Special Strategic Zones (NSSZ). In 2014, the same year as the Grand Design was presented, Japan approved the creation of six NSSZs with different specializations, such as medical innovation, agriculture, tourism, etc. (see fig. 1). The six zones are flanked with "regional innovation strategy promotion areas" such as the Industrial Cluster Programme, the Knowledge Cluster Initiative, and the Regional Innovation Strategy Programme. Notably, with regard to depopulation an explicit aim of the NSS is to stop the net inflow of currently around 100,000 persons per year from the rural areas to the Tokyo region (OECD 2016, MLIT 2015) and to encourage flows back to villages and smaller towns.

Despite the accomplishments attained by Japan's top-down national strategic spatial planning that has been applied over the last 60 years, there are growing doubts about the efficacy of its practice in the new millennium. The recurrent phenomena of industrial centralization and urban sprawl have shown how the location choices of both industry and households have consistently challenged the government's objectives of balanced growth and sustainable settlement patterns. This outcome has indeed created some degree of disillusionment with national spatial plans (OECD 2016).

However, withstanding all critique, the importance of coordinated, national-level strategic planning remains an imperative in Japan. In fact, at the beginning of the 21st century, in times of rapid change and insecurity, and "[...] at a time when government is devoting enormous energy to overcome traditional sectoral approaches to policy in favour of an integrated, government-wide approach to the challenges of demographic change, such a coordinating device is indispensable" (OECD 2016: 87). Also, it is believed that when national strategies are the outcome of extensive participatory processes, they can strengthen communication between stakeholders (OECD 2016). Drawing from this belief, the process of developing a national strategic plan is now considered in Japan to be as important as the plan itself-if not more so. This is also one of the reasons for the government's search for governance models that will enable more participatory decision-making processes in planning. 


\section{GOVERNANCE}

The need to engage with local municipalities and the requirement to work with multiple levels of government have contributed to two specific shifts in viewing governance in Japan. This section briefly outlines these two shifts. It is by no means a critique or a comprehensive review of citizens' (dis)contents; however, it points to a major shift taking place in this field (for more on new approaches toward governance, see Hamedinger in this volume).

\subsection{STRUCTURE OF TERRITORIAL GOVERNMENT}

The structure of the territorial government in Japan is built on the complex relationship between the central government and the subnational governments (for details, see OECD 2016). The Japanese archipelago consists of the main island (Honshu) and three major islands (Kyushu, Shikoku, Hokkaido) with 6,848 lesser islands, totaling $377,960 \mathrm{~km} 2$ in area. Administratively it is divided into 47 prefectures and 1,742 municipalities as of January 1, 2013. The three major metropolitan areas of Kanto (around Tokyo), Kinki (around Kyoto and Osaka), and Chukyo (around Nagoya) contain 51\% of Japan's total population (IPSS 2014). Cities in Japan have different statuses. With 9.6 million inhabitants (metropolitan region: 37.6 million), Tokyo has the status of a prefecture divided into 23 wards, which are seen as independent cities. The so-called "Designated Cities" have a population of over 500,000, the "Core Cities" more than 300,000, and the "Special Cities" over 200,000 people.

The enmeshment of fiscal structure and the commitment to interregional equity has created a very strong influence of the central government on subnational governments (OECD 2016). It is beyond the scope of this study to review the complexity of Japanese government and its evolution in recent decades; however, for this review, it is relevant to note that the current government is in search of a new approach to government (and governance), which will essentially instigate the devolution of power and the empowerment of local municipalities.

Figure 9: Structure of territorial government in Japan

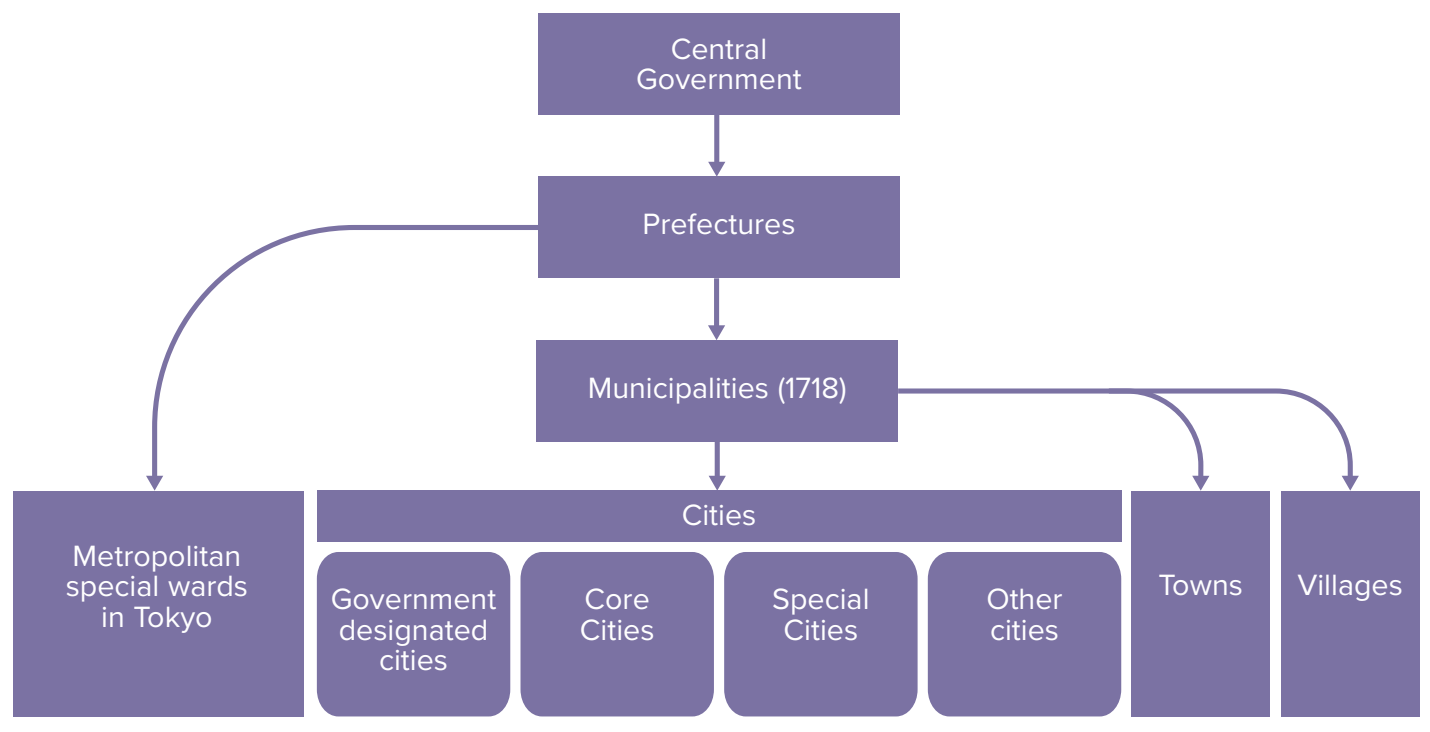

Source: OECD (2016) 


\subsection{TWO SHIFTS IN THE APPROACH TO GOVERNANCE}

The search for new models of governance intensified in Japan after the new Grand Design and the 2nd NSS were presented in 2014 and 2015 respectively. The main cause for this search was the institutional realization that the new national vision of a "compacted and networked" country could only be realized with the intense involvement of local actors and the production of local knowledge (OECD 2016). The central government is not expected to have the capacity be able to fully understand the specificities, assets, or constraints of local regions, let alone have the resources to innovate on that level. Two essential moves implied in the strategy are: (a) breaking away from the notion of transforming every region into a growth machine, and b) starting from the places and aspirations of the local community (and not solely investing in profit-oriented projects implemented in strategic locations).

Such discursive reflections have led to two shifts in looking at governance: (a) the shift away from a traditionally top-down approach to planning to one that encourages more bottom-up initiatives, and (b) the move away from sectoral to integrated policies.

\subsubsection{Top-down meets bottom-up}

While the old Grand Design for the 21st Century from 1998 had begun to promote wider citizen participation and partnerships, the first National Spatial Planning Act went on to institutionalize it in 2005. One of the intentions of this new act (see section 3.3) was to incorporate mechanisms of decentralization into Japan's national spatial planning system. It adopted a two-tier structure: the overarching National Spatial Plan (NSP) and eight Regional Spatial Plans (RSP; Kenji 2008: 511). This act consequently marked the beginning of the integration of local municipalities in the planning process. Based on this, many local authorities began to experiment with home-grown strategies, marking the growth of an experimental culture that would later prove supportive in developing local strategies for the deployment of CAVs.

After the "wake-up call" of the Masuda Report in 2014, a new consensus started to emerge across Japan: in order to respond to the diversity of the country's geographic, economic, and social challenges, it was assumed that while maintaining strong leadership from the center, a systematic acceleration of bottom-up processes in local communities was a matter of necessity. An important idea put forward by the new strategic approach is to encourage "healthy" competition and simultaneously foster strategic collaboration between subnational governments. To this end, the government has embarked on creating instruments to ensure that prefectural and local authorities have enough resources, know-how, and authority to design and implement their own ideas. It has also started a discussion on how new governance structures could improve the traditional tax allocation mechanisms enacted through the country's intergovernmental transfer system (OECD 2016).

\subsubsection{Breaking down the sectoral silos}

The second recommendation made by the new NSS is to break down the sectoral walls between governmental institutions:

These efforts are predicated in part on building on a sense of crisis (kikikan) in order to overcome institutional inertia and the tendency of bureaucratic structures to operate within narrowly defined sectoral policy 'silos'. There are important potential complementarities among different strands of public policy that can be only realized with a whole-of-government approach, and that is precisely what the government has been working to realize (OECD 2016: 79). 
"Breaking down the silos" seems to be an idea that had found its moment in Japan. It corresponds with another major institutional innovation initiated in the same year by the Council for Science, Technology and Innovation (CSTI)-something that would directly affect the programs for CAVs (see section 5.1).

\subsubsection{The "Headquarters": coordinating sectoral policies}

To enable the walls of sectoral silos to be broken down, the Japanese government created a new organization, also in the year 2014, called the "Headquarter for overcoming population decline and revitalisation of the local economy," in short "Headquarters." The mandate of this organization is to coordinate the national and regional policy interventions across all relevant policy domains and all sectors of the country. It was an organization put in place to build bridges across the deep rifts that exist or tend to grow in due time between sectors, organizations, and institutions.

The statement made by Prime Minister Shinzō Abe at the first meeting of the "Headquarters" in September 2014, denotes the importance placed in the role of this organization: "The most important aspect of measures to be implemented by this Council is that they eliminate vertical segmentation and employ one-stop responses [...]" (OECD 2016: 88). To further emphasize the importance of the organization, a new minister, directly under the aegis of the Cabinet Secretariat, was installed to head the organization. The "Headquarters" functions on two levels: (a) at the political level, it operates through a Council on Overcoming Population Decline and Revitalisation of the Local Economy chaired directly by the Prime Minister; and (b) at the working level, it operates through a staff of civil servants who support the minister with day-to-day operations (OECD 20016: 88). The minister is also in charge of the National Special Strategic Zones (NSSZ; see section 3.4.4); thus, he has the responsibility of aligning the country's population strategy, spatial strategy, and economic strategy. Also, he has to push and coordinate the local governments' mandate to create their own long-term visions and revitalization plans within the framework of the 2nd NSS in a participatory way-involving all key actors, including experts and civil society.

What makes the "Headquarters" interesting, is that it is instructed to offer both information (including big data) and financial support to local and prefectural authorities. If requested by the municipalities, the "Headquarters" is also obliged to appoint a civil servant with ties to the local region, who can for instance act as a consultant and advisor to the respective municipality (OECD 2016).

\section{CAVS IN JAPAN}

Japan is one of the key actors in the global innovation landscape for CAVs. Together with the USA and the European Union, it plays a strong political role in shaping the international discourse unfolding around CAVs. This is reflected in the yearly trilateral meetings conducted jointly by the three political regions. In this section we shall outline the country's institutional setting that enables the development of CAVs, its relation to NSS, and the experiments taking place in rural and mountainous regions. 


\subsection{THE SIP: AN INSTITUTIONAL CATALYST FOR CROSS-SECTORAL RESEARCH}

In 2014, an organization called SIP (Cross-Ministerial Strategic Innovation Promotion Program) was created by the Council for Science, Technology and Innovation (CSTI), under the auspices of the Prime Minister and the Minister of State for Science and Technology Policy, to facilitate transdisciplinary research by cutting through the ministerial silos (SIP 2017, Amano/Uchimura 2016). The key idea was to create a portfolio of programs and projects derived from an overall set of strategic goals and ambitions. The portfolio is divided into three general policy areas and eleven specific fields such as energy, disaster prevention, cyber security, etc. Each of these eleven fields is equipped with its own budget and ascribed a "program" led by a program director. The program directors' main function is to facilitate the cross-sectional coordination of the triple-helix movement between government (cross-ministerial), industry, and academia. They are responsible for the entire chain of activities from initiating basic research to a clear exit strategy (i.e., application and commercialization). One of these eleven policy areas, Next-Generation Infrastructure, is dedicated to automated driving systems (ADS). With the growing importance of ADS, SIP created a new section of its body called Automated Driving for Universal Services, in short SIP-adus, in 2014. The main objective of SIP-adus is to coordinate and catalyze research between a wide spectrum of actors, with the broader aim of integrating social innovation with technological innovation (Amano/Uchimura 2016). SIP-adus builds on the already existing national portfolios of Intelligent Transport Systems (ITS), Dynamic Map Planning, Human Machine Interface, Advanced Rapid Transit technologies (ART), and the projects of Next Generation Transport (for more, see Amano/Uchimura 2018).

\section{$5.2 \quad$ NSS AND CAVS}

As argued earlier, the reason for the detailed elaboration of the national spatial strategy is to explore how the spatial and functional logic for the deployment of CAVs has been derived from its comprehensive ideas of socio-territorial innovation.

Like most countries in the world, Japan's mobility sector is experiencing deep technological changes along with rapid changes in its citizens' mobility behavior. However, in addition to the globally shared challenges of decarbonization, lack of finance and accessibility, Japan's transport system is confronted with the challenge of serving a dramatic number of "disappearing municipalities"-a condition that is causing more and more transport services to close down, particularly in rural areas. In this dire situation, the promises of CAVs have greatly fueled the imagination of mobility experts in the country. CAVs in Japan are seen as a promising solution to many of its ailments. This circumstance makes Japan stand out sharply in the global race to deploy CAVs. The deployment of CAVs in Japan is not seen as a luxury but a necessity; its value is seen less as a private vehicle than as a public service.

As indicated in the sections above, the new Grand Design and the new NSS have also set the stage for conceptualizing the future of mobility in Japan. The new grand notion of a "compacted and networked" country requires an overall conception of new mobility systems-mainly on two levels: on one level, it needs to address intraregional mobility within "compacted" settlements, involving measures such as the reduction of cars and the promotion of public transport. On another level, it needs concepts for interregional mobility-those that will connect the compacted regions into strategic "networks." This will necessitate site-specific transit systems of very different types and capacities ranging from "platooning" to advanced rapid transit (ART), from personal mobility vehicles (PMV) to automated demand-responsive transport (ADRT). 


\subsection{CAVS IN RURAL JAPAN}

\subsubsection{Demand-responsive transport (DRT)}

Long before the advent of automated vehicles, Japan had been testing alternative concepts of mobility in rural areas (OECD 2016a). The proactive attitude of policy makers toward CAVs in Japan can be partly explained by the fertile ground that these experiments have cultivated. The most significant of these experiments have been conducted around the concept known as demand-responsive transit (DRT).

The mobility challenge for rural Japan (as also for similar low-density regions in many other parts of the world) is how to deploy quick, reliable, affordable transport options without requiring much public subsidies. To meet this challenge, municipalities started experimenting with the DRT model almost 40 years ago. In Japan, its system has evolved into one with three types of buses: (a) those with fixed routes, operating only if there is demand; (b) those that offer some flexibility in the fixed route; and (c) those that offer relatively free routes. Some places integrate taxis with flat rates for door-to-door services, and others offer bus services combined with shared taxis. Some 200 municipalities offer DRT services in Japan today. The rise of digital platforms led to a doubling of the provision of DRT between 2006 and 2013 (OECD 2016a: 238). The 2007 Act on Revitalization and Rehabilitation of Local Public Transportation Systems, and its amendment in 2014, gave municipalities more freedom to self-organize. This further "unleashed a great deal of local experimentation" in public transport, putting Japan at the "forefront of efforts to adapt public transport for rural areas" (OECD 2016: 236). Looking at the experiments conducted with CAVs in rural Japan, in fact, reminds us strongly of the DRT experience collected in the last decades.

\subsubsection{The main drivers for CAVs in rural regions}

Japan's proactive attitude toward CAV has mainly been sparked by (a) the hope of serving the mobility needs of an ageing society ("active ageing"), and (b) the hope of counteracting the problem of growing shortage of bus and truck drivers.

About 330,000 people aged over 65 years returned their drivers' licenses in 2016, after which it was found in a survey that about $70 \%$ of them felt a general reluctance to leave their homes (MLIT 2017; Amano/Uchimura 2016, 2018). In the context of this situation, the promotion of active ageing is, firstly, about how to deploy CAV in ways that could enable the elderly to play an active and productive role in society as long as they wish. Secondly, it is about reducing age-related fatalities, as $54 \%$ of victims of fatalities are 65 years of age or older (Amano/Uchimura $2016,2018)$. In fact, they are not only the victims of accidents but also the cause of accidents. This makes road safety involving the elderly one of the highest priorities in Japan.

The average share of the aged (65+) in rural areas is currently about $31 \%$, while the national average is about 23\% (MLIT 2017). This poses the question of how to maintain the provision of food, care services, etc. to the elderly in these increasingly depopulating areas of the country. As the public transportation market is liberalized in Japan, it is natural that companies should withdraw from the places where they cannot maintain profits. More than $13,000 \mathrm{~km}$ of bus routes have been canceled since 2007 (MLIT 2017). This situation is aggravated by the fact that both bus and taxi companies are finding it more and more difficult to recruit drivers in depopulating areas. The shortage of truck drivers (more than $40 \%$ of whom are aged over 50 ) has also started to make the delivery of daily provisions and other goods increasingly difficult. This has made both transit and delivery of goods highly interesting fields for site-specific and tailored applications for CAVs. 


\subsubsection{Experiments with CAVs}

Research and field operational tests (FOTs) with CAVs are initiated by SIP-adus along with national governmental organizations like the Cabinet Office, the Ministry of Land, Infrastructure, Transport and Tourism (MLIT), the Ministry of Economy, Trade and Industry (METI), or by local municipalities together with private companies and universities (for full report on all field operational tests from 2014 to 2018 , see SIP-adus 2019b). In 2018, 14 research locations were identified by the national government and 30 locations by local governments, universities, and private companies (MLIT 2019). A series of extensive tests built on fluid alliances forged between diverse sectors are currently underway in rural areas (MLIT 2019).

Figures 10-13: CAV tests at Keio University, Tokyo
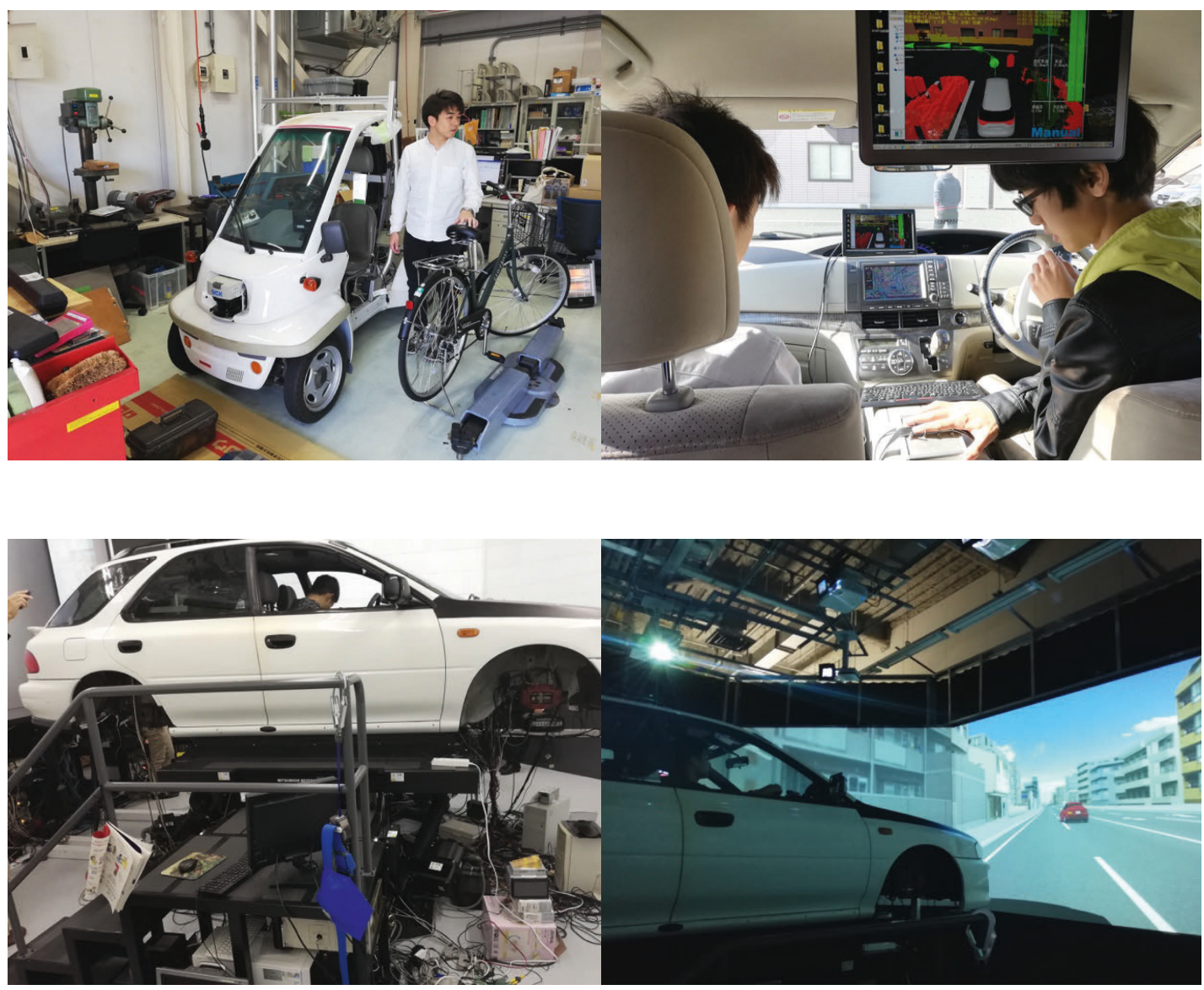

Photos: Ian Banerjee

\section{Experimental settings in rural areas}

Most of the experiments conducted by MLIT take place with four types of vehicles: two types of buses with the capacity of 6 passengers $(10 \mathrm{~km} / \mathrm{h})$ and 20 passengers $(35 \mathrm{~km} / \mathrm{h})$; a passenger vehicle for 6 passengers $(12 \mathrm{~km} / \mathrm{h})$ and a passenger car for 4 people $(40 \mathrm{~km} / \mathrm{h}$; see table 1 , figs. 14-17). They are guided by four different combinations of sensors: electromagnetic induction wire (EIW), 3D maps, global positioning systems (GPS), and inertia measurement units (IMU; MLIT 2019). 
Table 1: Details of vehicles and sensors for tests in rural Japan by MLIT

\begin{tabular}{|c|c|c|c|c|c|c|c|c|c|}
\hline & & Level 4 & Level 2 & GPS & IMU & $\begin{array}{l}\text { 3D } \\
\text { map }\end{array}$ & EIW* & $\begin{array}{l}\text { Passen- } \\
\text { gers }\end{array}$ & Speed \\
\hline Type I & Bus & $\bullet$ & & $\bullet$ & $\bullet$ & $\bullet$ & & 6 & $10 \mathrm{~km} / \mathrm{h}$ \\
\hline Type II & Bus & $\bullet$ & $\bullet$ & $\bullet$ & & & $\bullet$ & 20 & $35 \mathrm{~km} / \mathrm{h}$ \\
\hline Type III & $\begin{array}{l}\text { Passenger } \\
\text { car }\end{array}$ & & • & & & & $\bullet$ & $4-6$ & $12 \mathrm{~km} / \mathrm{h}$ \\
\hline Type IV & $\begin{array}{l}\text { Passenger } \\
\text { car }\end{array}$ & $\bullet$ & $\bullet$ & $\bullet$ & & $\bullet$ & & 4 & $40 \mathrm{~km} / \mathrm{h}$ \\
\hline
\end{tabular}

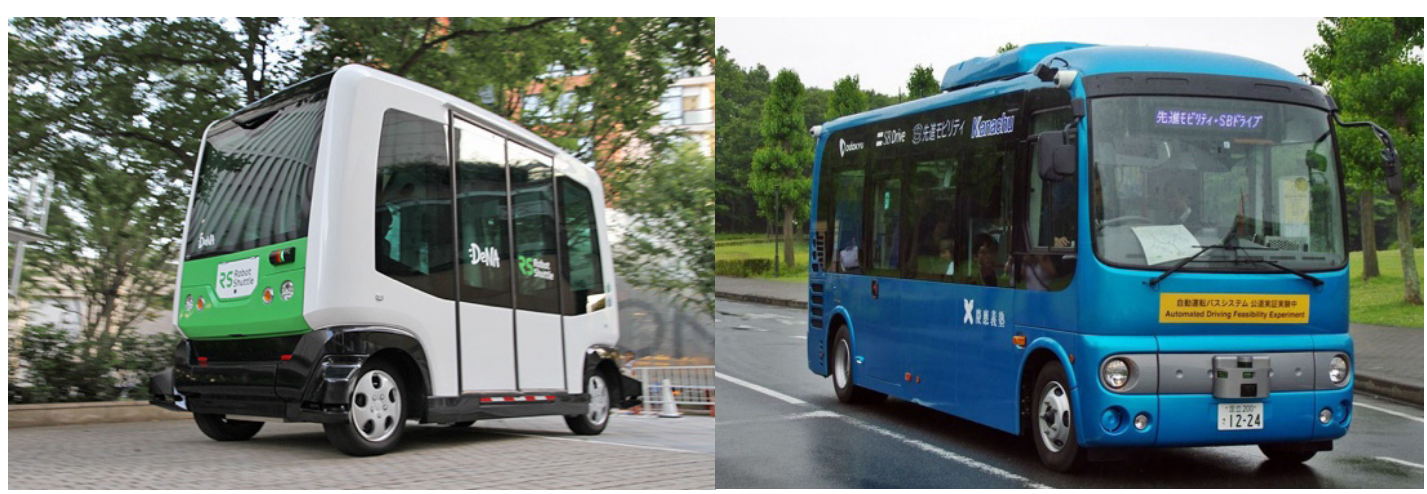

Type I

Type II

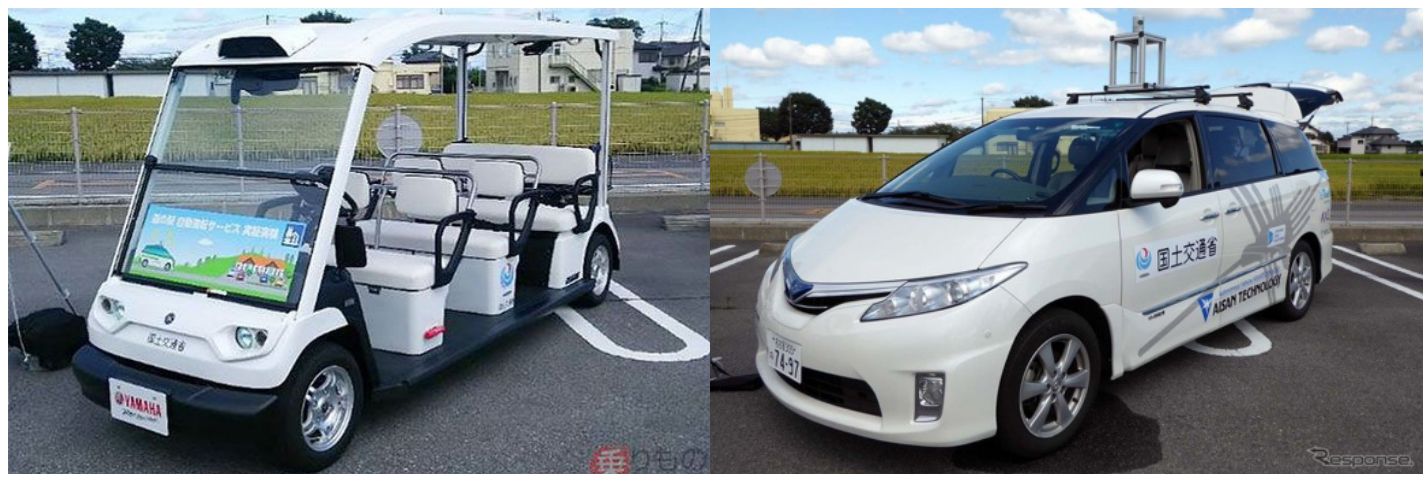

Type III

Type IV

Source: MLIT (2019)

The main purpose of the so-called "social experiments" conducted by MLIT (2017) are to understand the operational design domains (ODDs) and social needs involving (a) the necessary existing road environments for CAVs; (b) the existing transportation systems; (c) local specificities such as climate or telecommunication infrastructure; (d) the potential costs for scaling up the services; (e) social acceptance; and (f) the impacts on the lifestyle of especially elderly citizens. From a technological viewpoint, the main focus is on how to verify, develop, and maintain the dedicated traveling spaces, and also how to improve communication between vehicles and road infrastructure (V2I). From a business viewpoint, the feasibility of combining public transport and logistics is of special interest, as is the potential profitability of the respective cases. 


\section{"Roadside stations" in mountainous regions}

A series of CAV tests conducted in the mountainous regions of Japan exemplify the experimental setting of the tests in rural Japan. A number of them are located around "roadside stations" called "michi-no-Eki" (compare with the concept of "small stations" proposed in the Grand Design 2050 and 2 nd NSS, section 3.4.4). Located along main trunk roads, these roadside stations are more than just highway rest stops: they offer medical amenities, shopping facilities, and other essential services for everyday life. In Japan, the total number of roadside stations amounts to 1,167, of which more than $80 \%$ are located in rural areas (MLIT 2017). The experimental setting (fig. 18) simulates the real-life needs of the elderly in rural areas. The procedure is simple: The automated vehicles wait for local residents at the roadside station-also the place where the control center is located. Once an order has been placed via an app, a CAV picks up the client(s) from their home (or any given location) and takes them to do their errands, such as going to the clinic, shopping, or leisure activities. The customers are then transported back to their desired location.

Figure 18: Schematic diagram of the setting of social experiments with CAVs in roadside stations in rural regions

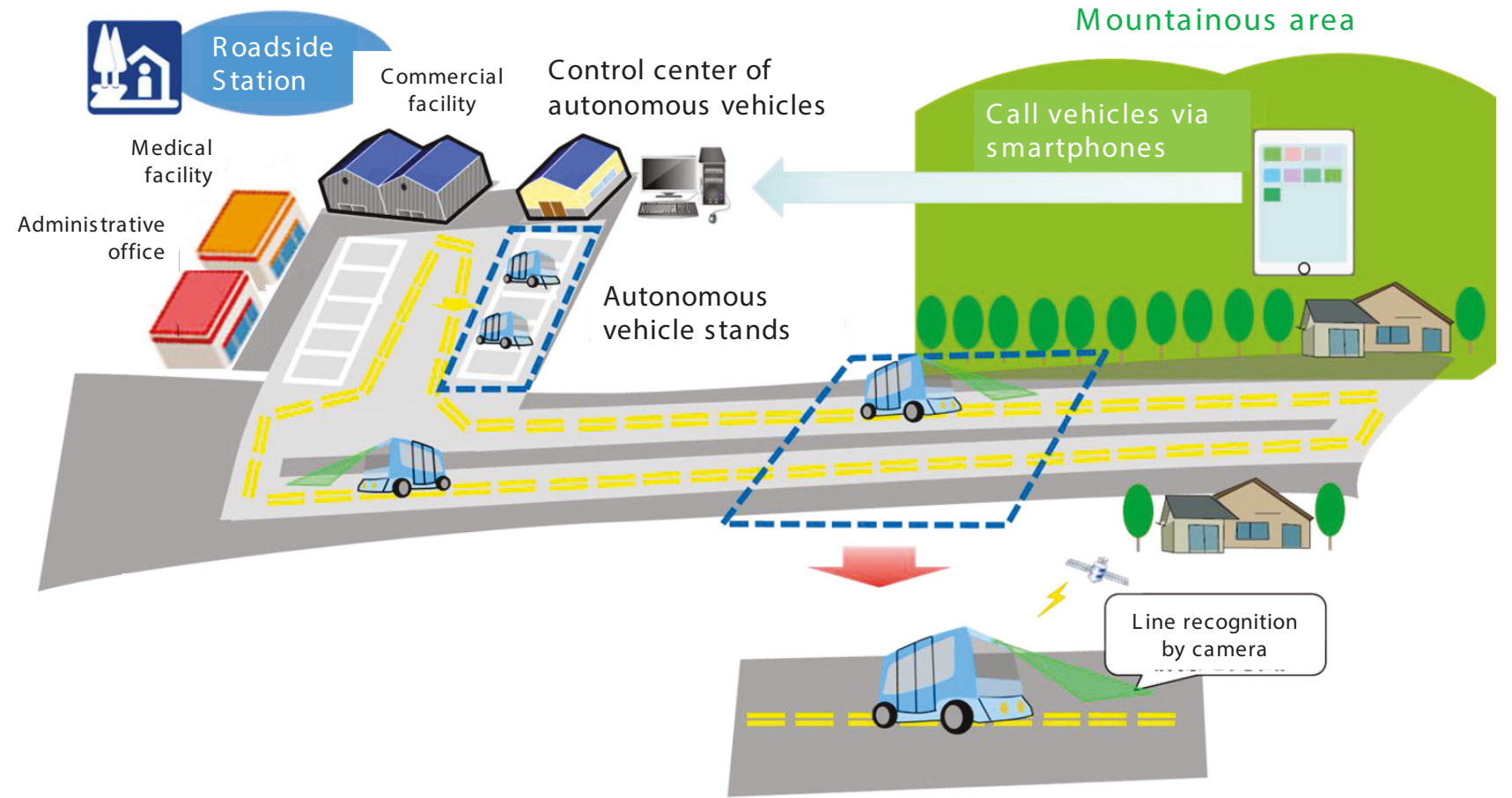

Source: MLIT (2017)

\subsubsection{Findings}

An interim report published by MLIT (2019) on the social experiments conducted in rural areas with hybrid forms of public transport and delivery systems, comprises an extensive evaluation of the tests undertaken from 2014 to 2018 . While no one can say how long it will take to scale up the tests, the findings give a clear picture of the thematic issues surrounding the social, technological, and financial feasibilities of the deployment of CAVs in rural areas. They can be summarized as follows:

1. Social needs: regarding the possible operational route for automated vehicles as public transport, three major types of needs for services are identified: (1) demand-type 
services that are personalized and completely flexible; (2) fixed-type services that are semi-flexible, for example, by allowing people to hop on and hop off the vehicles at flexible stops; and (3) the need for transfers to existing high-speed transit (first mile/last mile).

2. Social acceptance: (a) the perceived reliability of self-driving technology is significantly higher after boarding the vehicle than before; (b) people have feelings of uneasiness if the amounts of automated delivery are relatively small.

3. Road space: (a) operating on steep slopes in mountainous regions is technically possible; (b) narrow streets without sidewalks tend to hold up CAVs; (c) in mixed traffic, twolane streets are better for CAVs to handle than single lanes.

4. Technology: under snowy or foggy conditions, and in mountainous areas where GPS accuracy is reduced, CAVs utilizing vehicle-to-infrastructure technologies (V2I) such as electromagnetic induction wires (EIW) or magnetic markers showed better results than those using LiDAR.

5. Business models: (a) to make CAV more socially acceptable, it is necessary to make the operating entity, service models, and the definition of roles of providers and users more transparent; (b) the cooperation and coexistence with existing public transport services is absolutely essential (as complementary components); (c) annual budget calculations indicate that it is necessary to consider financing CAVs not only through fares and shipping charges, but also through various collaborations with private companies and subsidies from local governments; (d) collaboration with existing delivery and food distribution companies can improve the efficiency and cost of delivery of services in a given region; (e) it is necessary to educate users about the novel possibilities of using CAVs; $(f)$ it is important to illustrate to communities how CAVs can improve their local quality of life.

\section{CONCLUSION}

This paper has offered an analysis of how the current Japanese government is addressing the country's challenge of an ageing and radically shrinking population with a unified set of policy responses. The authors elucidated how the government is applying the instrument of a new national spatial strategy (NSS) as a navigational tool to orchestrate the development of the country's key economic and social sectors, including the deployment of technological novelties such as CAVs. The country's problems have led the government to align its entire technological funding and innovation program with the overall orientation of its new NSS. The research has shown that a national spatial strategy can be a helpful device to conceptualize a public-value-oriented deployment of CAVs-if the strategy has a cross-sectoral and multi-scalar approach, and if the strategy is the product of a broad and collaborative reimagining process.

Having peaked in 2010 , Japan's population is expected to plunge by $30 \%$ by 2060 . After two decades of intensifying debates on shrinking and mounting accusations of neglect on the side of the government, the nation's policy makers have finally found the political resolve to engineer a long-term vision for the country's future and a strategic plan for multidimensional change. Contrasting with the pessimistic mood prevailing in the country, the latest grand vision effuses new hope and an optimistic view of the future based on a plausible future scenario of "rightsized" cities and "smart shrinking" of regions. Two intertwined policy frameworks put for- 
ward by the Japanese government between 2014 and 2015, formulated an integral system of ideas and principles that were designed to fundamentally transform the country's approach to planning for the coming 40 years. The new strategy is framed by (a) a set of guiding principles that underlie the country's spatial development plan till 2050 (Grand Design 2050), and (b) an integrated national spatial strategy that stipulates the direction for the development of all the major sectors in the country till around 2025 (2nd NSS). All of Japan's future plans adhere to the system of ideas presented in these two key policy frameworks.

The authors investigated two defining features in the Japanese approach that make it an interesting case for studying the deployment of CAVs. The first feature pertains to how the country stands out among other proactive countries by the way it defines its experiments around CAVs as essential responses to its severe socioeconomic challenges-underlining the argument that CAVs are not a luxury for the few but potentially a common good for all. This makes public investment in the risk-prone technologies of automated driving systems (ADS) more arguable than in countries where relevant challenges are either not politically recognized or CAVs are not adequately defined as something that could create public value. The Japanese government's proactive attitude toward CAVs is mainly driven by the hope of meeting the needs of a rapidly ageing society, particularly in rural areas, and of solving the country's acute problem of its growing shortage of bus and truck drivers. In this context, it is interesting to note that the experiments taking place around CAVs are usually described as "social experiments" and not as technological experiments (MLIT 2017, 2019).

The second distinctive feature highlighted in the study pertains to how the new spatial strategy significantly shapes the rationale for the deployment of CAVs in Japan on both local and interregional levels. The case of Japan demonstrates that the deployment of CAV-based operations can be easier to conceptualize if a unified policy framework follows a principles-based and socio-spatially differentiated logic that responds to the challenges on all spatial scales of the country-from villages to megaregions. Such a unified and spatially differentiated logic has also made it easier for the Japanese government to deduce the logic for the countrywide deployment of CAVs and also to offer guidance to municipalities and local communities that aspire to cocreate their own CAV-based services. They are encouraged to act locally but think nationally. This study concludes by asserting that if an NSS is crafted strictly with the aim of addressing the country's challenges and of serving its public interest, then the deployment of CAVs can potentially be realized without the fear of commercial appropriation of the technology by a monopoly.

\section{Summary of the main elements of the strategy}

The authors have identified the following seven points that summarize (a) the aims, principles, and recommendations put forward by the New Grand Design 2050 and the 2nd NSS and (b) the key interim results from the experiments conducted with CAVs:

1. The principle aim of the unified national strategy is to ensure and maintain the country's high level of prosperity with fewer people. The National Grand Design 2050 makes recommendations about to how to reach this aim by (a) centralizing public services to make them more sustainable during the coming period of radical shrinking, and (b) decentralizing the economy by creating incentives to build a broad range of diversified and localized economic activities. The key ideas underlying the strategies' principles are presented as ideographic narratives that can be easily comprehended by all citizens (fig. 5).

2. The narratives of the two main policy-related principles employ the concepts of "compacting" and "networks." The long-term aim is to densify cities by "compacting" them ("rightsizing") and subsequently interlinking them into "networks" of cooperation ("smart shrinking"). The compacted centers are encouraged to become centers of social and 
technological innovation, networked by connectivity infrastructure of various kinds-this includes the infrastructure for CAVs.

3. Additional policy catchwords used in the strategy are: "revitalization," "diversity," "collaboration," and the "sixth industry." These terms refer to incentives created by the central government to motivate local municipalities to generate non-agricultural jobs in rural areas by encouraging them to tap into their own unique resources. The government has created a competitive situation where municipalities have to generate innovative ideas to vie for the limited resources provided to support their projects.

4. The unified spatial strategy envisions the restructuring of Japan with three types of spatio-functional building blocks based on three spatial scales, and three models of public services (figs. 6-7). These are: (a) villages served with "small stations" (for 10,000 inhabitants), (b) mid-sized cities served with "integrated regional hubs" (for 300,000 inhabitants), and (c) "super megaregions" served with "collaborative core urban areas" (for over 60 million people). These three spatial models can be seen as the "spatial DNA" of the strategic plan: their permutations and combinations are designed to produce and reproduce the socioeconomic spaces of human settlements and subsequently shape the entire territory of new Japan. It is important to note that this strategy looks at the urban-rural linkages of the country as a seamless spatial continuum.

5. New concepts for mobility are currently being reimagined both within and between the compacted settlements. The logic of deploying CAVs is closely intertwined with the systemic notion of spatial reconfiguration undertaken with the three aforementioned spatial building blocks. This can involve operational settings ranging from "platooning" to advanced rapid transit (ART), from personal mobility vehicles (PMV) to automated demand-responsive transport (ADRT).

6. Experiments with CAVs are currently being conceptualized with the following aims in rural Japan: to serve the ageing population; to attract young people by offering high quality of life; to make up for its growing scarcity of professional drivers; and to offer sustainable public transportation and freight services. Co-creative experiments with various use cases are being conducted in rural areas by the central government, municipalities, universities, and private companies. An interim report indicates that while there are serious "objective" needs for CAVs, there are many challenges to be met regarding road infrastructure, technology, operations, business models, and social acceptance.

7. Finally, Japan's approach to governance is changing in fundamental ways. The two ongoing shifts are: (a) the move away from a traditionally top-down approach to one that encourages more bottom-up initiatives, and (b) the move away from sectoral to cross-sectoral policies in order to create more synergies between the sectors. A bridging organization called the "Headquarters" was formed on the ministerial level to coordinate the task of orchestrating and streamlining the entirety of national and regional policy interventions and action programs across all relevant domains and sectors of the country.

While the 2nd NSS may arguably be the most comprehensive and ambitious spatial strategy plan proposed by a democratic government today, the results are yet to be seen. Bringing together all the country's key actors to implement the strategy remains a challenging exercise for the government. However, for the international discourse-particularly for Europe-it will be an interesting exercise to reflect and critically discuss the implementation of the Japanese strategy at this early stage as it responds to demographic and socio-spatial challenges that have started to afflict many parts of the continent in similar ways and with comparable severity. 


\section{LITERATURE}

Adams, G. 1981. The Politics of Defense Contracting: The Iron Triangle. New York: Routledge. https://doi. org/10.4324/9780429338304.

Agarwal, P. 2009. Walter Christaller: Hierarchical Patterns of Urbanization, Centre for Spatial Integrated Social Science. Santa Barbara: University of California. https://web.archive.org/web/20091105054923/ http://www.csiss.org/classics/content/67 (May 13, 2020).

Albrechts, L. 2004. "Strategic (spatial) planning re-examined," in Environment and Planning (31) 5, 743758. https://doi.org/10.1068/b3065.

Albrechts, L. 2006. "Bridge the gap: from spatial planning to strategic projects," in European Planning studies (14) 10, 1487-1500. https://doi.org/10.1080/09654310600852464.

Amano, H., and T. Uchimura 2016. "A National Project in Japan: Innovation of Automated Driving for Universal Services," in Road Vehicle Automation 3, ed. by G. Meyer and S. Beiker. Cham: Springer, 15-26. https://doi.org/10.1007/978-3-319-40503-2_2.

Amano, H., and T. Uchimura 2018. "Latest Development in SIP-Adus and Related Activities in Japan," in Road Vehicle Automation 4, ed. by G. Meyer and S. Beiker. Cham: Springer, 15-24. https://doi. org/10.1007/978-3-319-60934-8_2.

Bornstein, L. 2007. "Confrontation, collaboration and community benefits. Lessons from Canadian and US cities on working together around strategic projects," paper presented at the ISoCaRP conference, Antwerp, Sep 2007.

Broeck, P. van den 2011. "Analysing social innovation through planning instruments," in Strategic Spatial Projects - Catalysts for Change, ed. by S. Oosterlynck, J. van den Broeck, L. Albrechts, F. Moulaert., and A. Verhetsel. New York: Routledge, 52-78.

Christaller, W. 1933 (2009). Die zentralen Orte in Suddeutschland. Vienna: wbg Academic.

Diamond, J. 2019. Upheaval: How Nations Cope with Crisis and Change. UK: Random House.

Healey, P. 1997. "The revival of strategic spatial planning in Europe," in Making Strategic Spatial Plans: Innovation in Europe, ed. by P. Healey, A. Khakee, A. Motte, and B. Needham. London: UCL Press.

Healey, P. 2004. "The treatment of space and place in the new strategic spatial planning in Europe," in International Journal of Urban and Regional Research, 45-67. https://doi.org/10.1111/j.03091317.2004.00502.x.

IPSS (National Institute of Population and Social Security Research) 2014. "Chapter 1 Overview of Population Trends in Japan," in Social Security in Japan 2014. http://www.ipss.go.jp/s-info/e/ssj2014/001. html (May 22, 2020).

IPSS 2017. Population Projections for Japan (2017): 2016 to 2065. https://bit.ly/3buXAW2 (May 22, 2020).

Kaneko, H., and N. Kiuchi 2018. "National Grand Design and Spatial Policy in Depopulating Period," in KRIHS 36th Anniversary International Seminar, 6-38. http://www.nilim.go.jp/lab/jbg/depopulation/ others/natgradesspapol.pdf (May 12, 2020).

Kidokoro, T., H. Noboru, L.P. Subanu, J. Jessen, A. Motte, and E.P. Seltzer (eds.) 2008. Sustainable City Regions: Space, Place and Governance. Japan: Springer.

Kenji, O. 2008. "Challenges for a balanced and sustainable development in Japan," in Informationen zur Raumentwicklung Heft 8. Berlin: Bundesinstitut für Bau-, Stadt- und Raumforschung BBSR, 507-514.

Mitteregger, M., E. M. Bruck, A. Soteropoulos, A. Stickler, M. Berger, J. S. Dangschat, R. Scheuvens, and I. Banerjee (eds.) 2020. AVENUE21. Automatisierter und vernetzter Verkehr: Entwicklungen des urbanen Europas. Berlin: Springer Vieweg. https://doi.org/10.1007/978-3-662-61283-5_4.

MLIT (Ministry of Land, Infrastructure, Transport and Tourism) 2014. Grand Design of National Spatial Development Plan towards 2050 Japan. Tokyo. https://www.mlit.go.jp/common/001088248.pdf (May 22, 2020).

MLIT 2015. National Spatial Strategy (National Plan). Tokyo: Ministry of Land, Infrastructure, Transport and Tourism. https://www.mlit.go.jp/common/001127196.pdf (Apr 13, 2020).

MLIT 2017. Autonomous Vehicle Services in the Mountainous Regions around Roadside Stations (michino-eki). Tokyo. https://www.mlit.go.jp/common/001178887.pdf (Apr 19, 2020; in Japanese). 
MLIT 2019. Interim Report on Autonomous Vehicle Service in the Mountainous Regions around Roadside Stations. Tokyo. https://bit.ly/30tPrei (Apr 19, 2020; in Japanese).

Moulaert, F., A. Rodriguez, and E. Swyngedouw 2003. The Globalized City: Economic Restructuring and Social Polarization in European Cities. Oxford: Oxford University Press.

OECD 2012. Compact City Policies: A Comparative Assessment, OECD Green Growth Studies. Paris: OECD Publishing. https://doi.org/10.1787/9789264167865-en.

OECD 2015. Compendium of Productivity Indicators. Paris: OECD Publishing. https://doi.org/10.1787/ b2774f97-en.

OECD 2016a. OECD Territorial Reviews: Japan. Paris: OECD Publishing. http://dx.doi.org/10.1787/ 9789264250543-en.

OECD 2016b. OECD Territorial Reviews: Japan Policy Highlights. Paris: OECD Publishing. https://www. oecd.org/regional/regional-policy/Japan-Policy-Highlights.pdf (Apr 13, 2020).

Oosterlynck, S., J. van den Broeck, L. Albrechts, F. Moulaert, and A. Verhetsel (eds.) 2011. Strategic Spatial Projects: Catalysts for Change. New York: Routledge

Population Reference Bureau 2018. Which country has the oldest population? Based on Aging Demographic Data Sheet 2018 of International Institute for Applied System Analysis IIASA. Washington: Population Reference Bureau. https://bit.ly/38oAIFM (May 25, 2020).

Roland Berger 2018. Reconnecting the Rural: Autonomous Driving as a solution for non-urban mobility. Munich: Roland Berger. https://www.rolandberger.com/de/Publications/Reconnecting-the-rural-Autonomous-driving.html (Dec 14, 2019).

Reuters Graphics 2019. Going Grey. https://graphics.reuters.com/JAPAN-AGING/010091PB2LH/index. html (May 18, 2020).

Sassen, S. 1991. The Global City: New York, London, Tokyo. New York: Princeton University Press.

Schlappa, H., and W. J. V. Neill 2013. From Crisis to Choice: Re-Imagining the Future in Shrinking Cities. Saint-Denis: URBACT. https://bit.ly/3qyLv6o (Jul 23, 2020).

SIP 2017. What is the Cross-ministerial Strategic Innovation Promotion Program? https://www8.cao.go. jp/cstp/panhu/sip_english/5-8.pdf (May 2, 2020).

SIP-adus 2019a. “SIP-adus Workshop 2019." https://en.sip-adus.go.jp/evt/workshop2019/ (May 2, 2020).

SIP-adus 2019b. 2nd Phase of SIP-adus Project Reports 2014-2018. http://en.sip-adus.go.jp/rd/ (May 2, 2020).

Swyngedouw, E., F. Moulaert, and A. Rodriguez 2002. "Neoliberal Urbanization in Europe: Large-Scale Urban Development Projects and the New Urban Policy," in Antipode (34) 3, 542-577. https://doi. org/10.1111/1467-8330.00254.

Toshihiko, H. 2015. A Shrinking Society: A Post-Demographic Transition in Japan. Japan: Springer.

Warren, T. 1930. Population Problems. New York: McGraw Hill. https://doi.org/10.2307/1229783.

Webb, J. 2017. “Book Review: Japan's Population Implosion,” Tokyo Review, May 2, 2018. https://www. tokyoreview.net/2018/05/japans-population-implosion/ (May 2, 2020).

Open Access This article is licensed under the terms of the Creative Commons Attribution 4.0 International License (http://creativecommons.org/licenses/by/4.0/), which permits use, sharing, adaptation, distribution and reproduction in any medium or format, as long as you give appropriate credit to the original author(s) and the source, provide a link to the Creative Commons licence and indicate if changes were made.

The images or other third party material in this article are included in the chapter's Creative Commons licence, unless indicated otherwise in a credit line to the material. If material is not included in the chapter's Creative Commons licence and your intended use is not permitted by statutory regulation or exceeds the permitted use, you will need to obtain permission directly from the copyright holder.

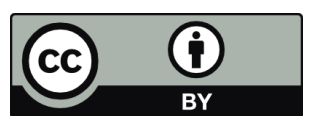

